\title{
Disaster-Risk, Water Security Challenges and Strategies in Small Island Developing States (SIDS)
}

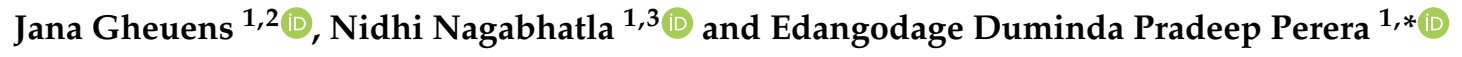 \\ 1 United Nations University Institute for Water, Health and Environment, 204-175 Longwood Road South, \\ Hamilton, ON L8P 0A1, Canada \\ 2 Institute for European Studies (IES), Vrije Universiteit Brussel, Pleinlaan 5, B-1050 Brussels, Belgium; \\ Jana.Gheuens@vub.be \\ 3 School of Geography and Earth Science, McMaster University, 1280 Main Street West, Hamilton, \\ ON L8S 4L8, Canada; Nidhi.Nagabhatla@unu.edu \\ * Correspondence: duminda.perera@unu.edu; Tel.: +1-905-667-5483
}

Received: 19 January 2019; Accepted: 12 March 2019; Published: 27 March 2019

\begin{abstract}
Small island developing states (SIDS) are typically characterized by being environmentally and socio-economically vulnerable to disasters and climate change. Additionally, they often have limited resources for freshwater provisioning services. This article presents an assessment of disaster risk and water security-related challenges in SIDS focusing on three major dimensions: (a) how disaster risks are perceived and addressed in the SIDS context using a case study method, (b) analyzing the current status of water security in these regions using an indicator-based approach and (c) assessing gaps and needs in institutions and policies that can facilitate sustainable development goals (SDGs) and targets, adaptation and resilience building in SIDS. In this regard, information on all SIDS is collected to be able to distinguish trends in and between SIDS based on amongst others geographical location and characteristics. This synthesis noted two key observations: first, that in SIDS, the number of disasters is increasing at a higher rate than the global average, and that the frequency and intensity of the disasters will likely increase because of climate change. These combined factors will impact SIDS on the societal level and on environmental levels, reducing their adaptive capacity, resources, and resilience. Second, most SIDS are already water-scarce with low groundwater volumes. Because of increasing demand (e.g., population growth and tourism) and decreasing supply (e.g., pollution and changes in precipitation patterns) freshwater resources are becoming increasingly limited, often suffering from the spillover effects of competing and conflicting uses. Threatened ecosystems and limited economic resources further influence the adaptive capacities of communities in SIDS. In this light, key solutions to address disaster-risk and water security-related challenges can be found by sharing best practices and lessons learned-from examples of good governance, integrated policies, improved community-resilience, and capacity-building. Added to their fragile situation, SIDS struggle to find enough funding to put their development plans, programs, and policies into action.
\end{abstract}

Keywords: climate change; disaster risk; policy; sustainable development goals (SDGs); small island developing states (SIDS); water security

\section{Introduction}

Small island developing states (SIDS) were first recognized as a distinct group of developing countries in 1992 at the Earth Summit in Rio de Janeiro, Brazil [1]. Although a set of characteristics or criteria for this geographical grouping was never defined, there is general agreement on the following set of features: small size, remoteness, vulnerability to external (demand and supply-side) shocks, 
narrow resource base, and exposure to global environmental challenges. Several lists of SIDS exist, but this paper follows the list of UN member state SIDS defined by the sustainable development goals (SDGs) knowledge platform. The list comprises 38 states (Figure 1), divided based on geographical location in the Caribbean, in the Pacific, and in the Atlantic, Indian Ocean, Mediterranean and South China Sea (AIMS). The SIDS overlap with the Alliance of Small Island States (AOSIS), a coalition of small island states that acts and negotiates together in the UN System [2].

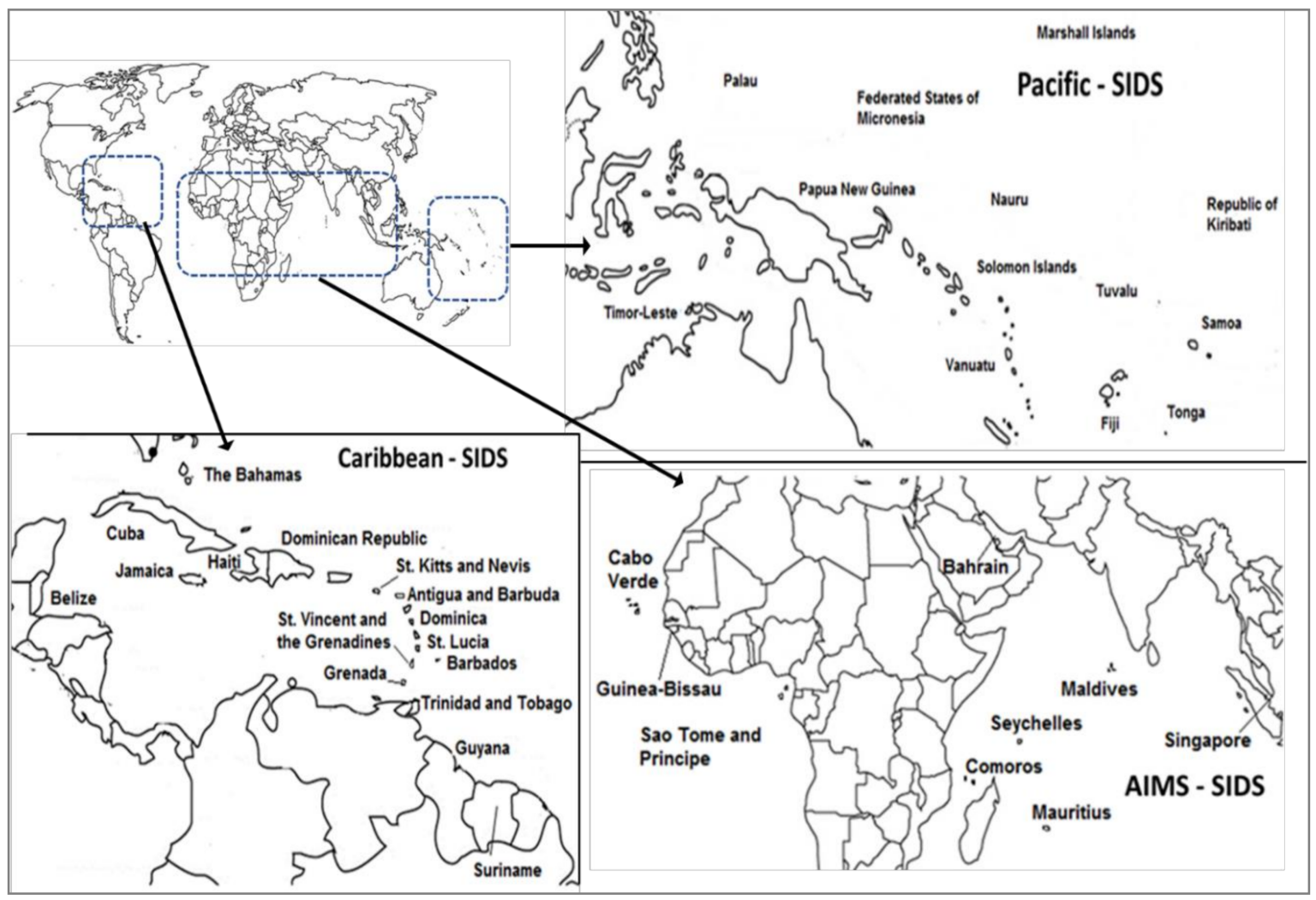

Figure 1. Map of small island developing states (SIDS)-geographical distribution of SIDS.

SIDS are highly vulnerable to natural disasters and impacts of climate change. The IPCC predicts that the intensity and frequency of disasters will further increase, impeding sustainable development and in some extreme cases making states uninhabitable [3,4]. Studies by the Water Resources Institute (WRI) and the Massachusetts Institute of Technology (MIT) predict that water scarcity will continue to increase in the future, with around $52 \%$ of the world's population living in water-stressed regions by 2050 [5,6]. SIDS will be particularly affected by this trend because of their vulnerabilities and already scarce freshwater resources. Most SIDS will experience a decrease in freshwater supply as the result of decreased rainfall, and an increase in demand, triggered by growth in population and tourism [1]. Tuvalu, for example, has already had problems with water supply in 2011 when it had no rain for six months, and 1500 of its population of 11,000 were left with no access to freshwater $[7,8]$. Australia and New Zealand brought in water and desalination units to help relieve the water crisis. These increasingly important challenges require good governance and adaptation to make sustainable development possible. Söjstedt and Povitkina [3] have shown that governance can influence the impact of natural disasters on SIDS. Boonreang (2015) offers some suggestions on how to improve governance and capacity-building; these include cooperation between different levels of government, increased training and resources for the public sector, and enhanced awareness and participation on the community-level [9]. Related, adaptation measures often focus on a specific biophysical or economic issue without attention to a more holistic view of disaster risk reduction (DRR), climate change adaptation, and water-security; this could lead to conflict, a duplication of measures, 
or even a complete overlooking of certain aspects of an issue [10]. As this paper touches upon, precise cooperation between levels and departments of government, and financial and technological issues remain challenges for SIDS. One way to overcome some of these issues is to focus on the community-level. UNESCO (2017) reports that this could lead to more information on vulnerabilities, impacts, and adaptive capacities of communities; better understanding of gaps and limitations of already existing programmes; and opportunities for empowering vulnerable groups such as women and youth [11]. Community participation can also help to include a more social understanding of resilience [10]. Often resilience is only seen as the capacity of an ecosystem to withstand and recover from damage. This neglects resilience as a social process and as the capability of communities to absorb changes.

This paper describes how disaster risk and water security issues impact socio-economic and political stability in these island states, how integrated policies on water provisioning and water-related disaster risk reduction can support them to adapt to climate change and encourage community-driven resilience, and what can be learned from best practices and successful interventions of water security planning and disaster risk reduction approaches. The article argues that strengthening governance has a positive influence on vulnerability to disasters and water security threats.

Previous literature mostly focuses on one geographic region or one aspect of disaster risk and water security; this article considers all SIDS and all the aspects of disaster risk and water security, to distinguish trends in and between SIDS.

\section{Methodology}

Natural disasters occur when a country's vulnerability to natural hazards damages society and the environment [12]. The definition by Söjstedt et al [3] was adopted, i.e., as "potentially damaging physical events or weather phenomena that may cause the loss of life or injury, property damage, social and economic disruption, or environmental degradation". The paper focuses mainly on water- and climate-related disasters: storms, floods, droughts, and tsunamis. Disaster risk reduction (DRR) are strategies used by decision-makers to reduce the vulnerability of a country to disasters, for example by enhancing disaster preparedness and applying more efficient management of natural resources. Adaptation measures are understood as policies that help adjust society to changing climatic conditions [10]. To understand DRR in the SIDS context, the Sendai framework for DRR, SDG 11.5 and SDG 13 on climate change, and the outlined targets and indicators are used (Appendix A) [13].

This paper follows the UN-Water definition of water security: "the capacity of a population to safeguard sustainable access to adequate quantities of acceptable quality water for sustaining livelihoods, human well-being, and socio-economic development, for ensuring protection against water-borne pollution and water-related disasters, and for preserving ecosystems in a climate of peace and political stability" [14]. In this light, water security can be seen as the tolerable level of water-related risks to society. The water security agenda, then, addresses a wide range of elements such as risks related to drinking water, ecosystems, climate change, water supply for food and energy production, governance, transboundary cooperation, political stability and financing [14]. To assess water security in SIDS, representative indicators are selected per element of the water security framework provided by UN-Water [15]. For example, for 'drinking water and human well-being,' indicators on access to improved drinking water and sanitation and dependence, availability and quality of groundwater are chosen to understand this aspect. The chosen indicators will then be aligned with the SDG portfolio-specifically with SDG 6 on clean water and sanitation (details in Appendix A), where possible. This makes the connection between freshwater resources and sustainable development.

A desk review and synthesis of existing data and publications of more than 500 sources was carried out to gain a better understanding of the status, vulnerability and risk aspects in the socio-ecological, socio-political and socio-economic context of SIDS. This paper then examines several representative case studies to demonstrate the successes that can be captured and gaps that need to be addressed for future development planning in SIDS. The first part of the assessment is based on a literature 
review of reports, policy documents, published articles and books. Multiple data sources, ranging from development organizations and government publications to academic literature, were used to get a comprehensive view of disaster-risk and water security challenges in SIDS. A second phase employs statistical data from sources such as EM-DAT and UNDP to analyze different trends in SIDS related to demographics, economy, disasters, environmental issues, and freshwater supply. To understand the needs and gaps related to disaster-risks and water security-related challenges a synthesis was made of the collected information.

During the assessment, data availability, data reliability and the language of data analytics arose as challenges. For example, in the Caribbean SIDS, most data are available only in Spanish which makes it difficult to collect and analyze. Also, it is noted that SIDS often do not have the capacity to collect rigorous data on the impacts of natural disasters and climate change, which will ultimately affect the assessment.

\section{Assessment of Disaster Risk and Water Security in SIDS}

\subsection{Disaster Risks as Perceived and Addressed in the SIDS}

According to the IPCC, SIDS have a disproportionately higher vulnerability to and risk of natural disasters [16]. In SIDS the number of registered water- and climate disasters rose from 212 (1978-1997) to 377 (1998-2018), an increase of almost 178\% (see Figure 2), compared to an increase of $151 \%$ globally [17]. While there was an increase in disasters, the number of disaster-related deaths has gone down in the last decade. This could be attributed to better safety measures and early warning systems [18]. Studies also have shown that the number of deaths will most likely be higher in less democratic and more economically unequal countries, showing already some of the effects of governance and capacity-building on resilience. The main water- and climate-related disasters in SIDS discussed in this paper are storms, floods, droughts, and tsunamis. Storms are the most frequent disasters, followed by floods, droughts, and finally tsunamis [17].

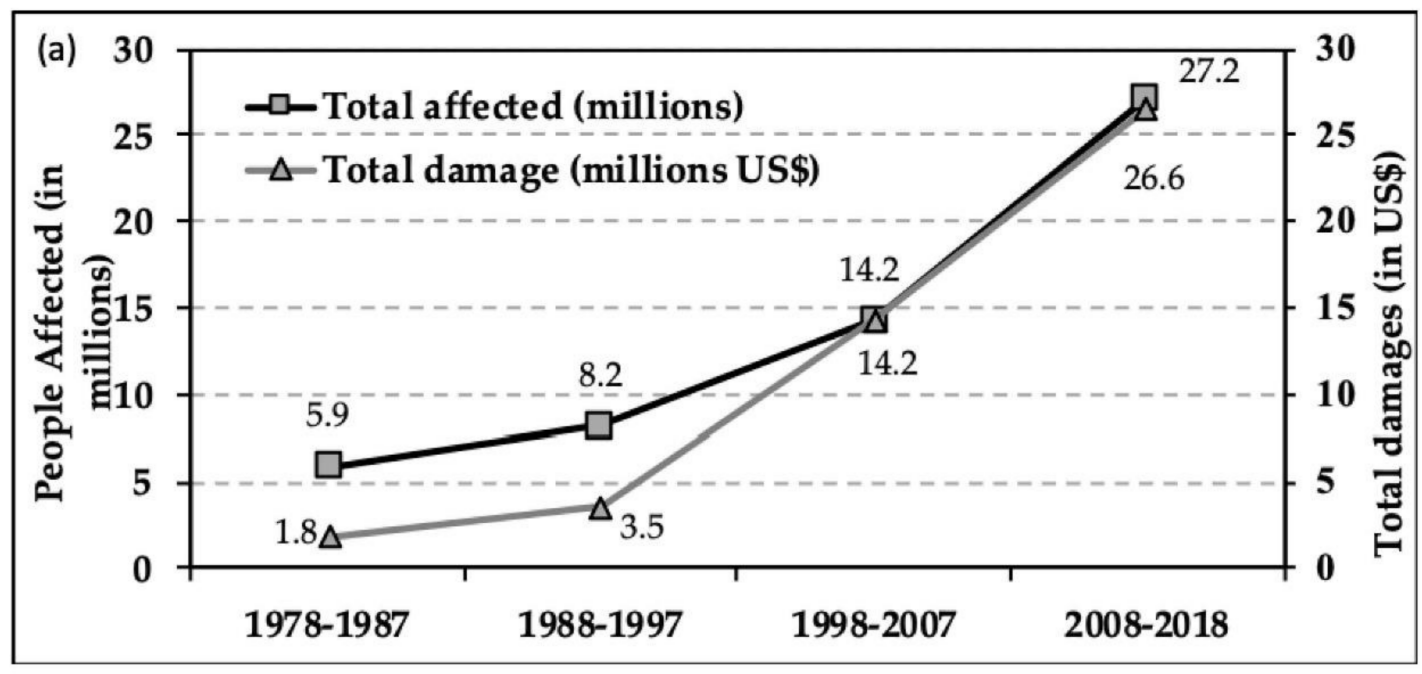

Figure 2. Cont. 


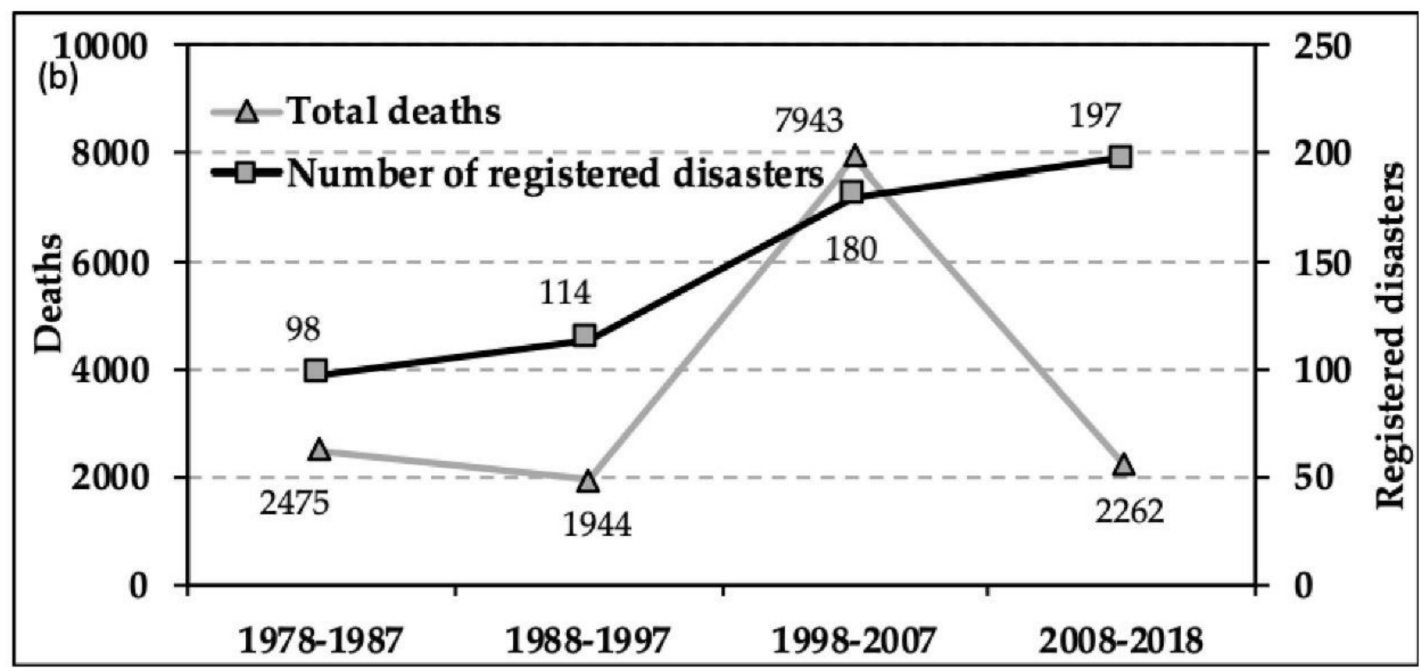

Figure 2. (a) Trends in number of people affected and total damages in SIDS; (b) Trends in numbers of deaths and registered disasters in SIDS [17].

While in AIMS storms account for $41 \%$ of the disasters (see Figure 3), more than $50 \%$ of these storm disasters have occurred in Mauritius. Similarly, most (nearly half) of the droughts in the AIMS region occurred in Cabo Verde. Excluding these two cases, epidemic disasters are the most common in AIMS. Both in the Pacific and the in the Caribbean, storms are the most frequent disaster type.

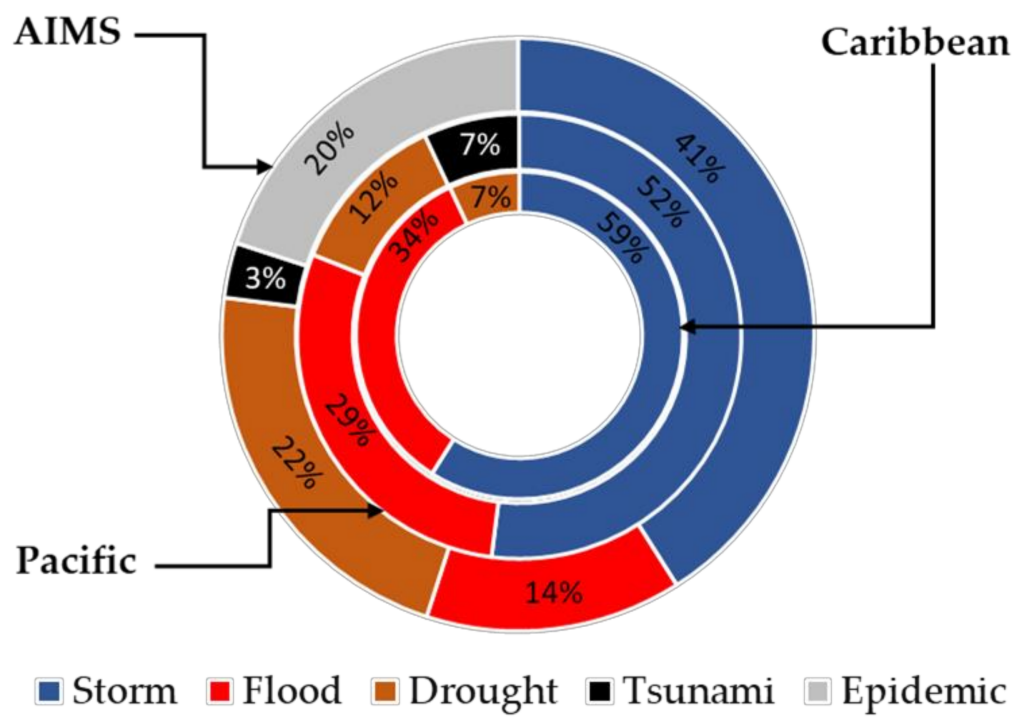

Figure 3. Types of disasters in SIDS (Atlantic, Indian Ocean, Mediterranean and South China Sea (AIMS), Pacific and Caribbean) [17]. AIMS depicted in the outer circle have exposure to all five types of disasters while the SIDS in Caribbean expose to droughts, floods and storms only.

Many of the climate-related disasters are due to changes caused by excessive or limited rainfall. These are often related to climate change or climatic events such as El Nino and La Nina, adding another factor that leads to high variability in rainfall in SIDS, especially in the Pacific. Most scenario studies reflect that SIDS in the Caribbean and AIMS regions can expect less precipitation in future years $[16,19]$. It is harder to establish clear trends for SIDS in the Pacific; for example, the Marshall Islands are expected to have an increase in rainfall while Fiji is expected to have a decrease. In almost all SIDS, rainfall is irregular in space and time, meaning that some parts or islands will receive more rainfall than others and that rainfall is not distributed evenly within a year. It is important to note that even if SIDS are projected to have an increase in rainfall, it may refer to higher intensity in rainfall 
within a short period, thereby increasing the risk of flooding during wet season, while not decreasing their risk of droughts during dry periods.

Population growth in urban areas, and coastal settlements increase the exposure and vulnerability to disasters in SIDS. Almost all SIDS (84\%) have had population growth in recent years; an increased population means more people are exposed to and will likely be affected by natural disasters $[20,21]$. It can also lead to an increase in economic losses. Where people live matters when it comes to exposure and vulnerability. There has been an increase in urbanization of around 1.7\% in SIDS, with $56 \%$ of the population already living in urban areas [22]. The Pacific has the highest increase in urbanization with $4.7 \%$. Contrary to global trends of urbanization, this does not always mean an increase in GDP, and in many SIDS, there is only one urban area. As SIDS only have limited land resources; settlements (many informal) are often built in environmentally sensitive areas such as flood plains. Urban areas, especially informal ones, are more vulnerable to disasters in general. Added to this, most of the population and the economic activities of SIDS are in coastal areas that are highly exposed to coastal flooding, tsunamis and hurricanes. Without the necessary capacity, the mix of increased vulnerability in SIDS because of climate change and demographic changes, can lead to a dangerous cocktail that can have disastrous effects on the lives of many on the islands.

Disasters affect SIDS socio-economically and environmentally. Socio-economically, disasters cost SIDS a lot in damages and recovery $[17,23]$. They can also cause disturbances in critical economic sectors such as fisheries, tourism, and agriculture. The tourist industry is especially vulnerable to natural disasters as the majority of tourist infrastructure is in coastal zones. Furthermore, less tourist arrivals can be seen after a disaster hits a country [24,25]. Economic losses are often exacerbated by the geographical isolation of many of the SIDS, making it hard and expensive for disaster relief to reach the islands [26]. Because of the isolation, in an immediate aftermath of a disaster, many SIDS have to fend for themselves as relief aid will take some time to reach the affected islands. Besides the loss of employment, impacts of disasters on society include death and injury, reduction of food security and the destruction of infrastructure. These impacts can have long-lasting effects; for example, the destruction of schools or the use of schools as shelters, can hinder children's education. In Fiji, coastal flooding and climate change leads to the loss of beaches people use to play rugby-one of the country's most important sports, strongly connected to Fijian society and the culture of "vaka vanua" (the way of the land) [27]. The loss of the beaches often means not being able to train enough which affects Fijian sense of identity and community. Because of the increased occurrence and frequency of natural disasters, communities might not be able to fully recover from a disaster before the next one occurs, further increasing the vulnerability of SIDS and hindering their sustainable development [28].

Environmentally, drastic landscape change and loss of ecosystems because of natural disasters impact SIDS the most. SIDS are characterized by fragile endemic ecosystems that have crucial roles to play in adaptation measures. The loss of their ecosystem-services has therefore detrimental effects on human society and the environment. Environmental degradation in its turn can lessen the resilience of SIDS against future disasters, trapping them in a vicious circle [29]. For example, tropical storms can damage coral reefs, reducing the adaptive capacities of the islands [30]. In extreme cases, disasters have entirely wiped out islands, as illustrated by the flooding of small islands during Cyclone Winston in Fiji [31]. As discussed above, many informal settlements are in environmentally sensitive areas showing the high vulnerability of the poorest groups in society that often do not have the capacity to adapt to the changing circumstances.

Some SIDS are more affected than others. As Table 1 shows, the most affected SIDS are all located in the Caribbean (except Papua New Guinea), demonstrating the region's vulnerability to natural disasters. Between 1970-2010, the frequency of disasters increased by $372 \%$ in the Caribbean [32]. 
Table 1. Most affected small island developing states (SIDS) countries in 2008-2018 and 1998-2017 [17].

\begin{tabular}{|c|c|c|c|c|}
\hline 2008-2018 & $\begin{array}{l}\text { Number of } \\
\text { Disasters }\end{array}$ & Damages & People Affected & Deaths \\
\hline 1 & Haiti (39) & Cuba (\$19.4 million) & Cuba (11.1 million) & Haiti (1622) \\
\hline 2 & $\begin{array}{l}\text { Dominican } \\
\text { Republic (26) }\end{array}$ & Haiti (\$2.3 million) & Haiti (7.6 million) & $\begin{array}{l}\text { Papua New } \\
\text { Guinea (108) }\end{array}$ \\
\hline 3 & Cuba (13) & Dominica (\$1.9 million) & $\begin{array}{l}\text { Dominican Republic } \\
\text { (3.0 million) }\end{array}$ & Dominica (94) \\
\hline 1998-2007 & $\begin{array}{l}\text { Number of } \\
\text { Disasters }\end{array}$ & Damages & People Affected & Deaths \\
\hline 1 & Haiti (33) & Cuba (\$6.1 million) & Cuba (10.5 million) & Haiti (6507) \\
\hline 2 & Cuba (21) & $\begin{array}{l}\text { Dominican Republic } \\
\quad \text { (\$2.5 million) }\end{array}$ & $\begin{array}{l}\text { Dominican Republic } \\
\quad(1.2 \text { million })\end{array}$ & $\begin{array}{c}\text { Dominican } \\
\text { Republic (1261) }\end{array}$ \\
\hline 3 & $\begin{array}{l}\text { Dominican } \\
\text { Republic (18) }\end{array}$ & Bahamas (\$2.3 million) & Haiti (0.9 million) & $\begin{array}{l}\text { Papua New } \\
\text { Guinea (240) }\end{array}$ \\
\hline
\end{tabular}

As all the SIDS regions have high risks of natural disasters, moving forward with sustainable DRR strategies and early warning systems is essential. On the global level, some initiatives and agreements focus on the importance of DRR strategies. The Sendai framework for DRR 2015-2030 has formulated some targets regarding the establishment of multi-hazard management in disaster risk including: "Reduce direct disaster economic loss in relation to global gross domestic product (GDP) by 2030; substantially reduce disaster damage to critical infrastructure and disruption of basic services, among them health and educational facilities, including through developing their resilience by 2030; increase the availability and access to early warning systems, and substantially increase the number of countries with national and local disaster risk reduction strategies by 2020." [13].

SDG 11 and 13 have similar targets on DRR strategies $(11.5,13.1)$ (see Appendix A). The progress SIDS make towards reaching the targets can be a good indicator of the DRR measures in place. The Data Readiness Review is the first part of the monitoring process of the Sendai Framework. If data is not available or accessible, it will be hard to measure any progress made towards reaching the targets. Only the following SIDS completed the Sendai framework data readiness review 2017 between 20 February 2017 and 20 April 2017: Antigua and Barbuda, Federated States of Micronesia, Guyana, Maldives, Mauritius, Saint Kitts and Nevis, Saint Vincent and the Grenadines, Tonga, and Trinidad and Tobago [31]. Barbados, Nauru, and Tuvalu partially completed it. The Pacific SIDS have set up a Pacific Sendai framework monitor to measure disaster losses to increase the available information for policy-making, coordination and disaster preparedness [32]. The Sendai framework monitor builds further on the Pacific disaster loss database and the framework for resilient development in the Pacific and has links to the SDGs. That only nine SIDS completed the Data Readiness Review is a first indicator that SIDS encounter challenges when it comes to collecting data on natural disasters. It also shows the importance of capacity-building to be able to fully understand how SIDS are impacted by natural disasters. One way to get clearer picture on what is happening, is to strengthen the community-level. Gathering communities' local knowledge is the first step towards a broader understanding of the vulnerabilities of exposed communities [10]. With this knowledge mitigation and adaptation measures will likely be more effective. Another way to improve DRR strategies is to enhance the exchange of information between different levels of governments themselves, between governments and non-state actors, and between states [9].

As mentioned above, natural disasters and climate change are often linked. The most frequent disasters (storms, floods, and droughts) are climate induced. Therefore, many DRR strategies can also serve as climate change adaptation strategies. One of these measures could be ecosystem management, with the example of mangrove planting that protects against sea-level rise, coastal flooding and land 
erosion. SDG 13 has several targets on integrating climate measures into other policies and capacity building. Climate change also poses different risks, such as sea level rise, land and forest degradation, desertification, rising of ocean temperatures and loss of biodiversity that can affect SIDS resilience to natural disasters [11]. Vice versa, natural disasters can decrease SIDS adaptive capacity to climate change. Because many economic activities are in coastal areas with tourist industries, sea-level rise among others can further increase SIDS's vulnerabilities and damages.

\subsection{Analysis of Water Security in SIDS Using an Indicator-Based Approach}

To discuss water security in SIDS, this paper adopts the Water Security conceptual framework developed by UN-Water [15]. The framework incorporates different elements of water-security such as 'drinking water and human well-being, ecosystems, water-related disasters and climate change, and economic activities and development' that are looked at in a broader context of "good governance, transboundary cooperation, financing, and peace and political stability" [15]. The elements from the water security conceptual framework (Figure 4) are addressed in two groups, based on synergies in underlying challenges: (a) water, sanitation and hygiene (WASH), climate change, disasters and ecosystems; (b) cooperation for shared water systems, economic development, financing, political stability and governance.

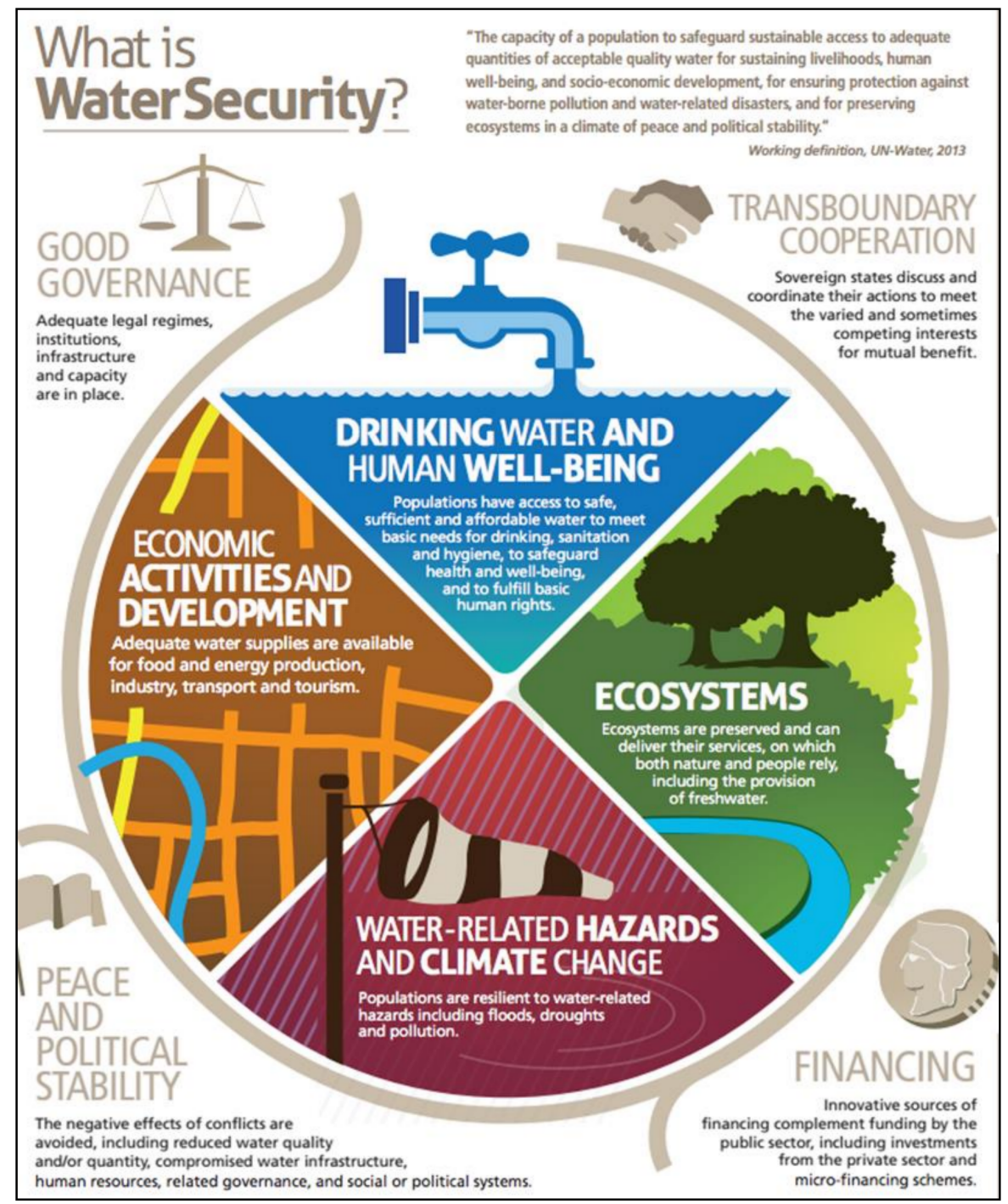

Figure 4. The water security conceptual framework of UN Water (2013) serving as the guiding approach to assess water security in SIDS [15]. 


\subsubsection{Water, Sanitation, and Hygiene (WASH), Climate Change, Disasters and Ecosystems}

To assess whether populations have access to safe and sufficient WASH provisioning, we refer to SDG 6.1 and 6.2 indicators on access to water and sanitation, and their targets 6.1.1 and 6.2.1 on the proportion of the population that uses safely-managed drinking water and sanitation, and the human dependence on and quality of groundwater (Appendix A).

As shown in Figure 5, most of the population in SIDS have access to improved drinking water and sanitation, with a few exceptions such as Haiti and Papua New Guinea [33]. Some cases, such as Sao Tomé and Principe, show a big difference between the provision of drinking water and the provision of sanitation services. Improved drinking water is defined as: "piped water into dwelling, yard, or plot; public tap or standpipe; tube well or borehole; protected dug well; protected spring; or rainwater collection" [33]. Most of these drinking water sources are basic, meaning that they are located within $30 \mathrm{~min}$ (round trip) of people's home [34]. In almost all SIDS, these figures have improved from 2000. Contextual issues can vary from state to state, for example in the Solomon Islands access to improved drinking water decreased in the 2000-2015 period due to civil unrest and a devastating tsunami, and in Papua New Guinea, $42 \%$ of the population still relies on untreated surface water [34,35].

In general, a lower percentage of the population has access to improved sanitation, meaning sanitation that separates human waste from human contact [33,34]. Around 70\% of SIDS have basic managed sanitation services in which excreta are not safely deposited. Only one-third of SIDS' populations report having sewer connections, and only $59 \%$ of wastewater is subjected to secondary water treatment. In Haiti and Nauru, $20 \%$ of the population-one person in five-has access to limited sanitation services, meaning they must share improved sanitation facilities and that waste is not properly disposed. Pacific SIDS is the only region in the world where open defecation is still a persisting challenge. It is important to note that the statistics on improved drinking water and sanitation can hide shortfalls or interrupt the supply of water for example during dry periods [36]. Poor access to drinking water and/or sanitation can cause some issues for vulnerable groups in society such as women. For example, Amnesty International [37] published a report on the violence against women in the Solomon Islands. In the slums, women and girls often have to walk more than $1 \mathrm{~km}$ to fetch water for domestic purposes; by doing so they run a high risk of being assaulted or raped, especially at night as the pathways to water supply and sanitation are poorly lit.

Most SIDS have some water infrastructure facilities in place (dams, rainfall harvesting, wastewater recycling, etc.), depending on their geographic characteristics and resources. Mountainous SIDS, often with access to water through rivers, seem to invest primarily in dams. Low-lying SIDS are generally more focused on rainwater tanks. During the dry season, there can be a deficit in water availability, especially in SIDS that have limited freshwater resources. The present of the infrastructure alone is not enough to make a thorough evaluation of accessibility to drinking water. If the infrastructure is not well-maintained or the rainfall is less, it affects to the availability of water resources quantitatively and qualitatively. In Trinidad and Tobago, for example, some $48 \%$ of water unaccounted-for water is due to leakages and illegal water connections [38]. In this context, the dependence on, the availability of and the quality of the groundwater are also essential to understand the availability of freshwater. For example, in the Caribbean, some countries have a high reliance on groundwater that is of poor quality [39]. This can cause water availability issues. SIDS in the Caribbean have experience significant differences in groundwater volumes. Some Caribbean SIDS are water scarce, while Jamaica has vast groundwater reserves. In the Pacific region, problems could arise because of a high or medium human dependence on groundwater and small groundwater volumes. In Tuvalu, for example, the reliance on groundwater is high, even though it has only a groundwater volume of $4.0 \times 10^{-4} \mathrm{~km}^{3}$ [40]. In the AIMS cluster of SIDS, the dependence on groundwater is limited. 


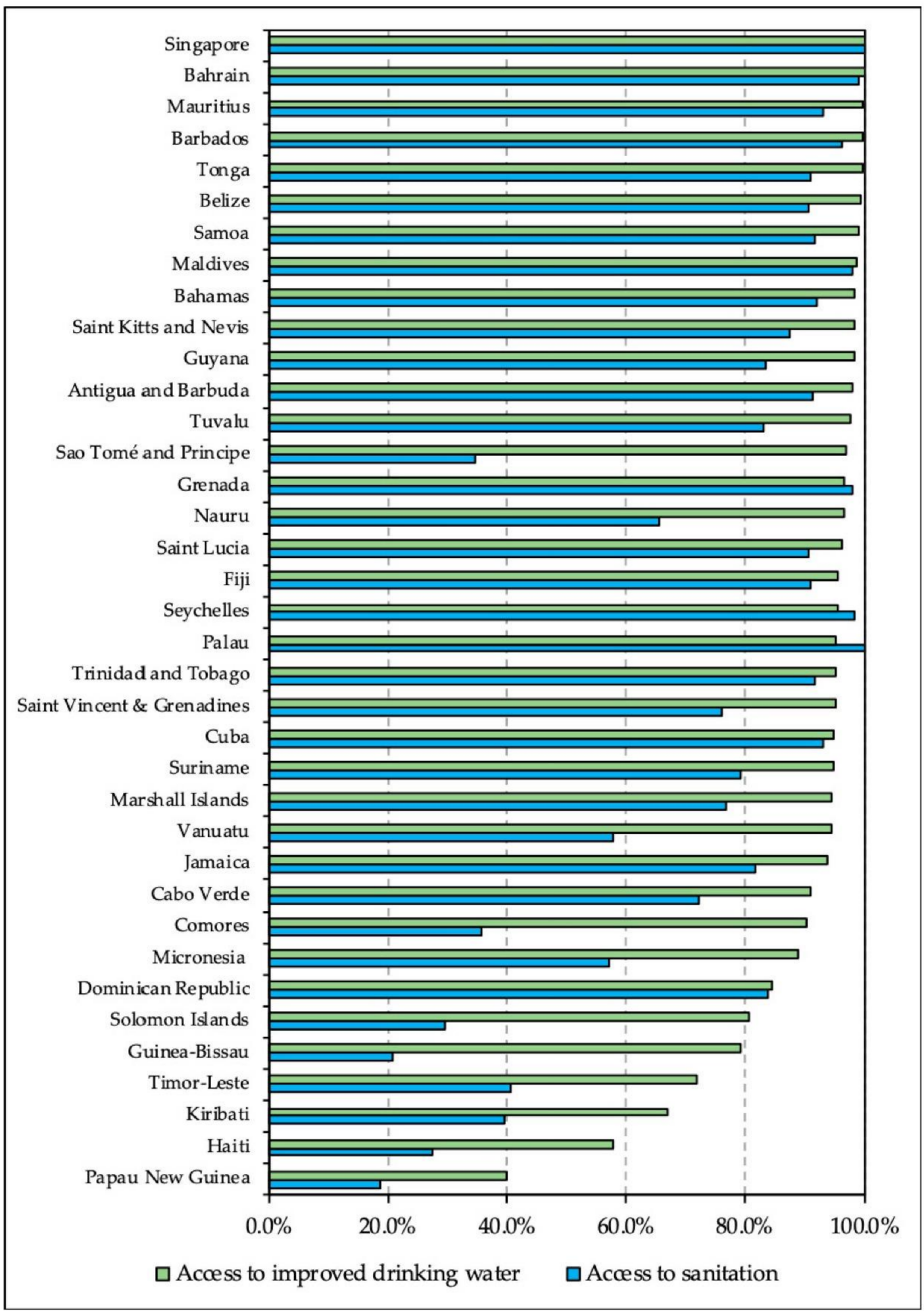

Figure 5. Access to improved drinking water and improved sanitation in SIDS [33].

Climate change and natural disasters play a central role in understanding the access to and availability of freshwater in SIDS. It is beyond argument that climate change will increase hydrological instability and the intensity and frequency of weather events, leading to increase in heavy precipitation in some regions, elevating the risk on flooding; and a decrease in precipitation in other regions, increasing the risk on droughts [16,41]. Different types of flooding in the case of SIDS include flash flooding, coastal flooding, fluvial flooding and tsunamis. Flooding affected $\sim 9.2$ million people in SIDS 
from 1990 until 2018 from which $~ 6066$ lost their lives [17]. The damages caused by flooding amounted to up to 1.6 million USD. Tsunamis mostly affect the Pacific islands; between 1990 and 2018 they caused 2891 victims in SIDS with 12 causalities. The damages cost the affected SIDS 0.52 million USD. Droughts mainly pose a risk to SIDS with limited groundwater resources that have limited alternatives for freshwater access. Additionally, droughts often cause increased salinization of groundwater, polluting the scarce sources that are available [42-44]. Climate change-induced trends and patterns also impact socio-economic stability. For example, sea-level rise can cause an increase in coastal flooding and lead to seawater intrusion. Combined with the fact that a high percentage of communities in SIDS live in areas less than 5-10 m above the sea level and a lot of their economic activities are concentrated in coastal areas, sea-level rise can increase vulnerability to coastal flooding and the economic cost attached to it.

Anthropogenic changes such as urbanization can further impact the availability of freshwater resources. An increase in urbanization impacts freshwater resources by increasing demand for freshwater, destroying ecosystems, and an increasing discharge of wastewater (often untreated) and pollution. However, urbanization needs to be viewed in the broader economic and societal context of a country. For example, both Singapore and Nauru are completely urbanized, but the impacts of it are vastly different [33]. Additionally, the expansion of human settlements into environmentally-sensitive areas, combined with population growth will decrease the resilience of SIDS to and will increase the damages of changes in water availability especially when ecosystems and biodiversity are affected $[42,45,46]$. The ecosystem context is reflected in the water security framework, highlighting its essential role in maintaining the quantity and quality of available freshwater [15]. Additionally, ecosystems also rely on freshwater for their survival. As Figure 6 shows, ecosystems and biodiversity are already under stress in SIDS, signaling that more and improved protection mechanisms are needed to safeguard them. Uncontrolled urbanization without proper waste infrastructure can also gravely deteriorate the quality of freshwater resources [47]. Most of the AIMS and the Caribbean SIDS already have a moderate to high risk for groundwater pollution not only because of sewage but also because of seawater intrusion, agricultural chemicals and other types of waste [48]. 


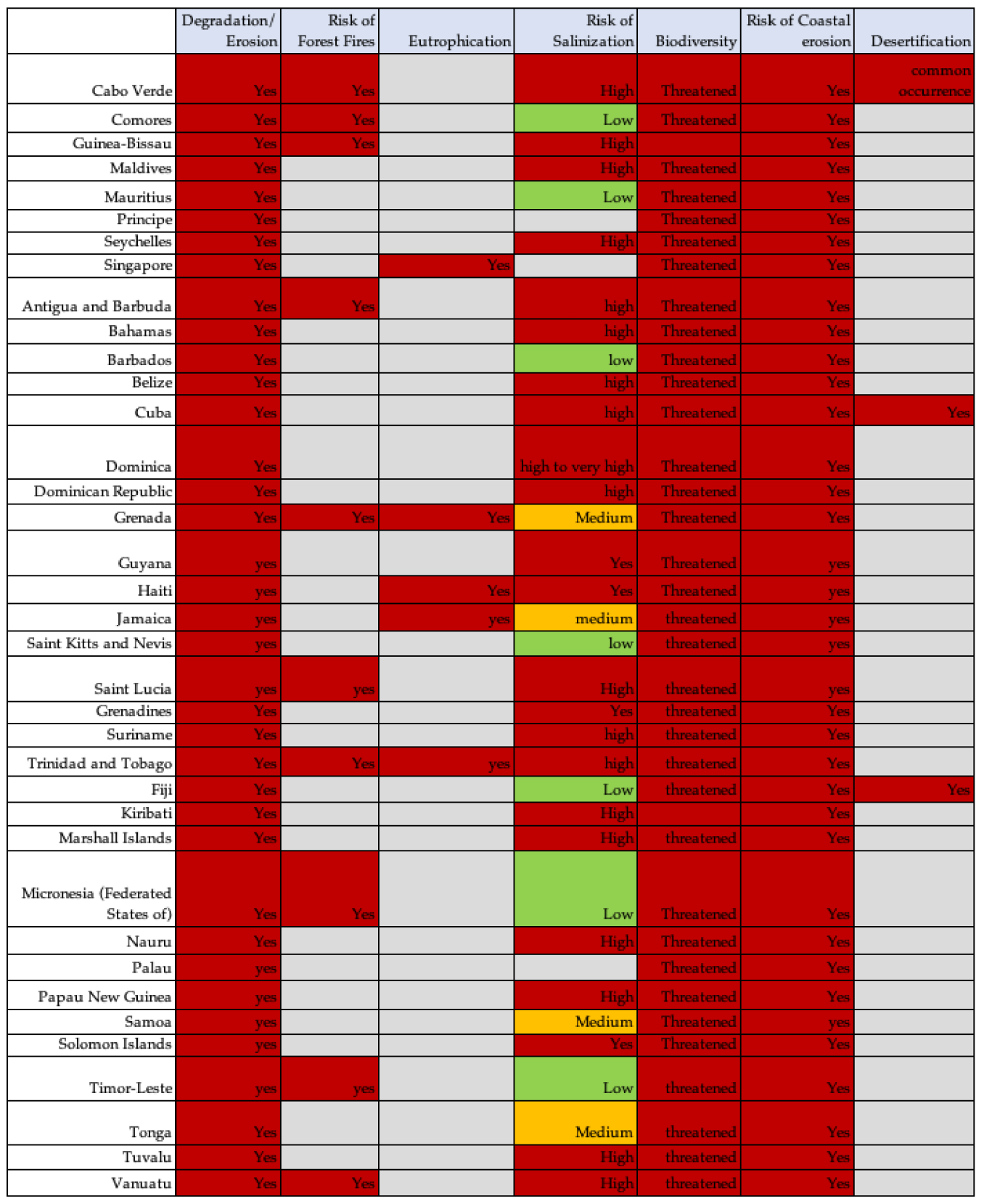

Figure 6. Overview of SIDS score on selected indicators primarily depicting the ecosystem aspect of the water security framework (gray color cells represent no data found) $[33,39,49,50]$.

3.2.2. Cooperation for Shared Water Systems, Economic Development, Financing, Political Stability, and Governance

This cluster of parameters from the water security framework covers a range of dimensions relevant for planning water security and SDG 6 goals and targets. SDG Indicator 6.5 .2 on operational arrangements for transboundary water cooperation and target $6 \mathrm{a}$ on international cooperation and support for capacity-building, etc. (see Appendix A). Most states, except Singapore, Belize, Dominican Republic, Haiti, Guyana, Suriname, and Papua New Guinea, are island states without transboundary water basins or agreements. Therefore, the water cooperation focus as part of the water security framework is limited. However, some regional and global partnerships exist, such as the Pacific Regional Environment Programme (SPREP) and the Project Integrating Watershed and Coastal Area Management (IWCAM) in the Caribbean. These are only two of the many partnerships and projects SIDS have agreed upon between themselves [51]. Although cooperation between SIDS can help with 
capacity building and improving governance, the partnerships often face challenges related to funding, the geographic isolation of the islands and cultural differences between SIDS.

Economic activities and development are another critical element of the water security framework, particularly managing water supplies for food and energy production, industry, transport, and tourism and balancing the different needs can be a challenge. For SIDS, this dimension is crucial as they have a high economic vulnerability with limited opportunities for revenue generation due to their small populations, geographical isolation, and limited resource bases. According to data of the World Bank [52], Caribbean SIDS show an economic growth between 2\% and 5\% of their GDP. This is a slight decrease compared to the value registered in 2000. Pacific SIDS have shown GDP growth. Studies show that climate disasters can negatively impact the GDP [30]. For example, Dominica suffered economic damages up to $200 \%$ of its GDP after the hurricane season of 2017 [53]. Debt levels of SIDS are often directly related to the high economic and environmental vulnerability of these islands. For example, after the financial crisis of 2009, SIDS experienced a decline in tourism which significantly affected their economic growth [54]. Of all the regions, the Caribbean SIDS have the highest debt percentage $(76 \%$ of their GDP in 2014), followed by the AIMS region (65\%) and the Pacific (33\%) [55]. In the past decade, debt levels have continued to grow. High debt levels pose a challenge as they limit the capabilities of SIDS to invest in better infrastructure to enhance their resilience and to further their development.

As SIDS often have low domestic revenues and are generally not that attractive to private investors, official development aid (ODA) is a valuable financial resource for development and adaptation to climate change and natural disasters [56]. SIDS receive around 3\% of global ODA, population wise this accounts for 3.8 times higher ODA per capita than other developing countries [57]. The geographical isolation and remoteness also add to transportation costs and hinder establishing market value chains. Therefore, the cost to deliver the development aid is also 4.7 times higher, significantly lessening the ODA per capita that reaches the SIDS. Of the financing, 79\% comes from bilateral provides, as SIDS often struggle to, or are not eligible to apply for global funds. However, several funds exist that support SIDS in becoming more resilient to climate change and often improved water resources management is a part of these efforts. For example, the Maldives receives financing from the Adaptation Fund to strengthen water resources management [58]. The Global Environmental Facility (GEF) also funds three projects each in a different geographical cluster of SIDS to support the formulation and implementation of national plans for integrated water resource management (IWRM). Additionally, from 2011-2014, overseas development assistance funds for climate issues to SIDS doubled; it now accounts for some $14 \%$ of total development aid to these geographic entities [56]. Most of the funding aims for climate change-related adaptation measures.

For many SIDS, tourism is an integral part of their economy and an essential source of financial resources [59]; in the Caribbean, tourism accounts for $12.9 \%$ of employment, in the Pacific for $12.4 \%$ [60]. Some countries such as the Maldives depend on it (directly and indirectly) for $80 \%$ of their GDP. From 2000, the number of tourists visiting SIDS has increased from 28 to 41 million in 2013 [61]. Although tourism can have a positive impact on the economy of island states, it can also increase its environmental vulnerabilities. Development and use of coastal environments for recreational activities and tourism can further deteriorate and pollute sensitive ecosystems and by doing so destroying its future tourism potential. Tourism can also put pressure on the already limited resource base, especially on freshwater resources. As shown in Figure 7, in some SIDS there are more than two tourists for every resident visiting the island every year, possibly pressuring the freshwater resources and ecosystems, more so when there is no proper management or when policies are not executed appropriately. A best practice SIDS can learn from is the Maldives; tourist resorts often have their own desalination plants to put no additional stress on the country's limited fresh water resources [62]. Additionally, if the waste produced by tourist activities, either on the islands or from shipping, is not probably disposed of, it can pollute the groundwater and other water resources, increasing the water scarcity of the islands [59,61]. Increased pollution in its turn, will also discourage future tourists from visiting certain SIDS, thereby impacting their vulnerable economic growth. Climate change and disasters can also 
decrease tourism by affecting ecosystems, resources, and infrastructure. Other important economic sectors are the agricultural industry, and fisheries $[57,60,63]$. All of these have in common that they are highly vulnerable to climate change and that they could impact each other. Tourism, for example, could harm the agricultural industry by occupying land that was first used for growing food. Livestock and the use of fertilizers, in its turn, could lead to eutrophication which is harmful to fisheries. The effect they have on each other does not need to be negative; through the green or blue economy, for example, they could all benefit from each other.

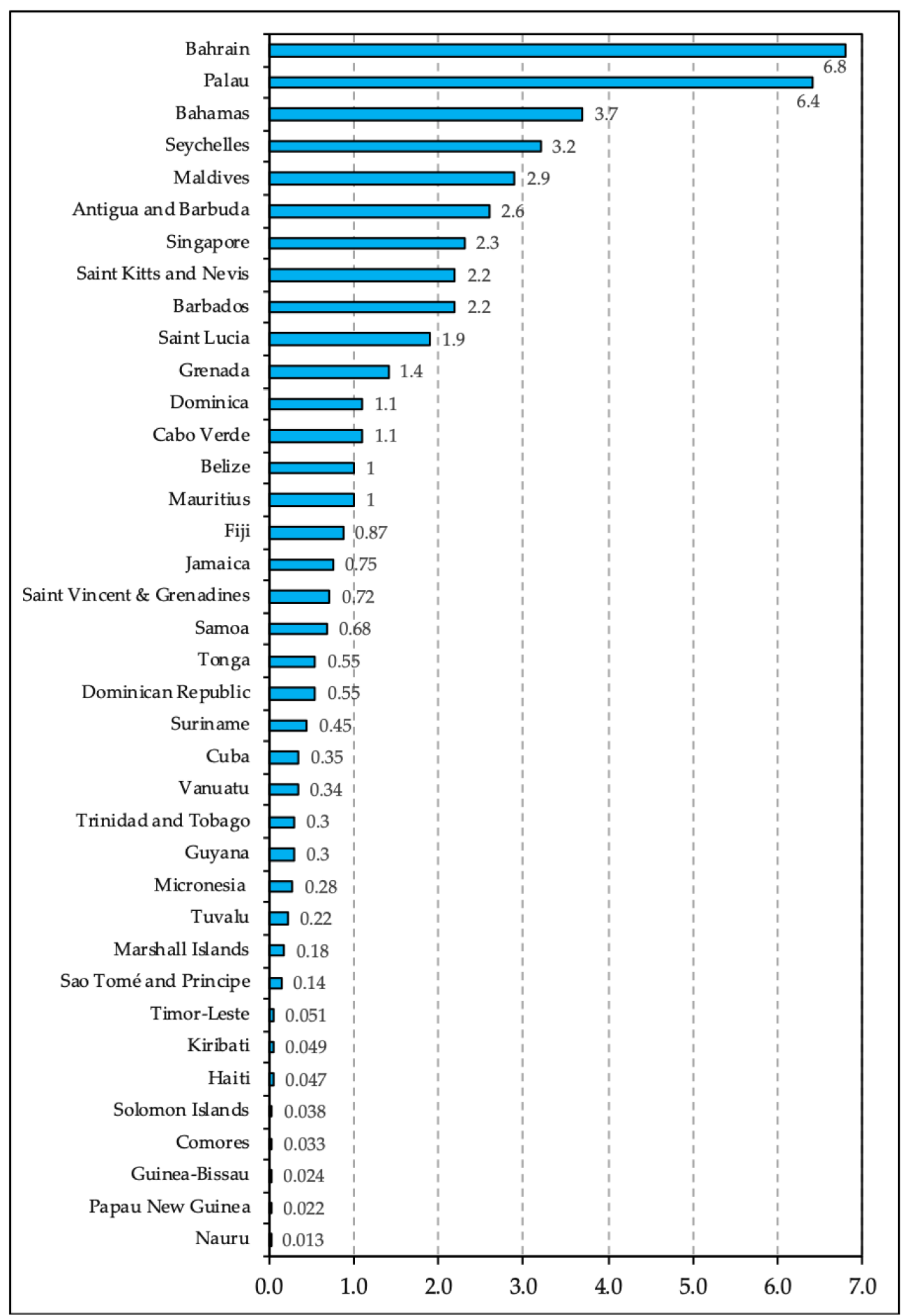

Figure 7. Tourists per resident in SIDS, the indicator reflecting the additional water stress in the context of tourism [64]. 
Water management is both necessary for economic growth and a consequence of economic growth $[5,65]$. As water is essential for all production, effective water resource management cannot be underestimated as a determinant for sustainable development. Additionally, poverty and social instability are exacerbated by low levels of water security and can lead to further environmental degradation. As SIDS are mostly poor and water scarce countries the cost for water resource management is already high, ecological degradation can increase the challenges they already face. Therefore, to fully understand water security in SIDS, it is pertinent to assess some reflective indicators of political stability viz., unemployment and poverty rates, and the gender context.

Noting the key development trends in the island states, youth unemployment (rates can be as high as $50 \%$ ) is a growing concern in SIDS, mainly because of the gap between the educational system and the job market $[1,54,66]$. The spillover impacts include all kinds of issues ranging from teenage pregnancies, drug-use, crime and violence- detrimental to the political stability. Correlating the percentage of the population living below the poverty line, with the unemployment rate can provide additional perspectives to the water and climate-related challenges (Figure 8). Countries with a low unemployment rate still can have notable poverty. In Vanuatu, for example, some $40 \%$ of the population lives in poverty, while their unemployment rate is only $1.7 \%$. Additionally, SIDS have some of the world's highest emigration rates $[33,67]$. Many of the migrants are highly-skilled, and the brain drain in SIDS is on average higher than $50 \%$, in some SIDS even up to $75 \%$. This leads to the loss of human capital in SIDS and contributes to poverty. In the Solomon Islands, high unemployment has proven to be a potential trigger for civil, social and often political conflict [68]. Women are often overrepresented in unemployment and poverty rates because of gender discrimination, customary laws and traditional gender roles [69]. In most SIDS women are responsible for fetching water for domestic use, impacting the time they can spend on education, training and paid labor, while also affecting their health. Paths to water resources can also be unsafe and can endanger women and girls using them, as demonstrated by Amnesty International's report on the Solomon Islands discussed above [37].

Water crisis scenarios and climate change-induced trends and patterns also impact social and political stability. Studies show that a combination of high unemployment and lack of participation in governance can lead to people voicing their concerns through riots [70]. In the Solomon Islands in 2014, riots broke out close to an evacuation center after a flood disaster [71]. People from both the evacuation center and neighboring communities plundered shops. It is also reported that non-flood victims entered the camps to receive some of the relief support. They are again showing the importance of good governance and the necessity of proper adaptation measures and DRR strategies. 


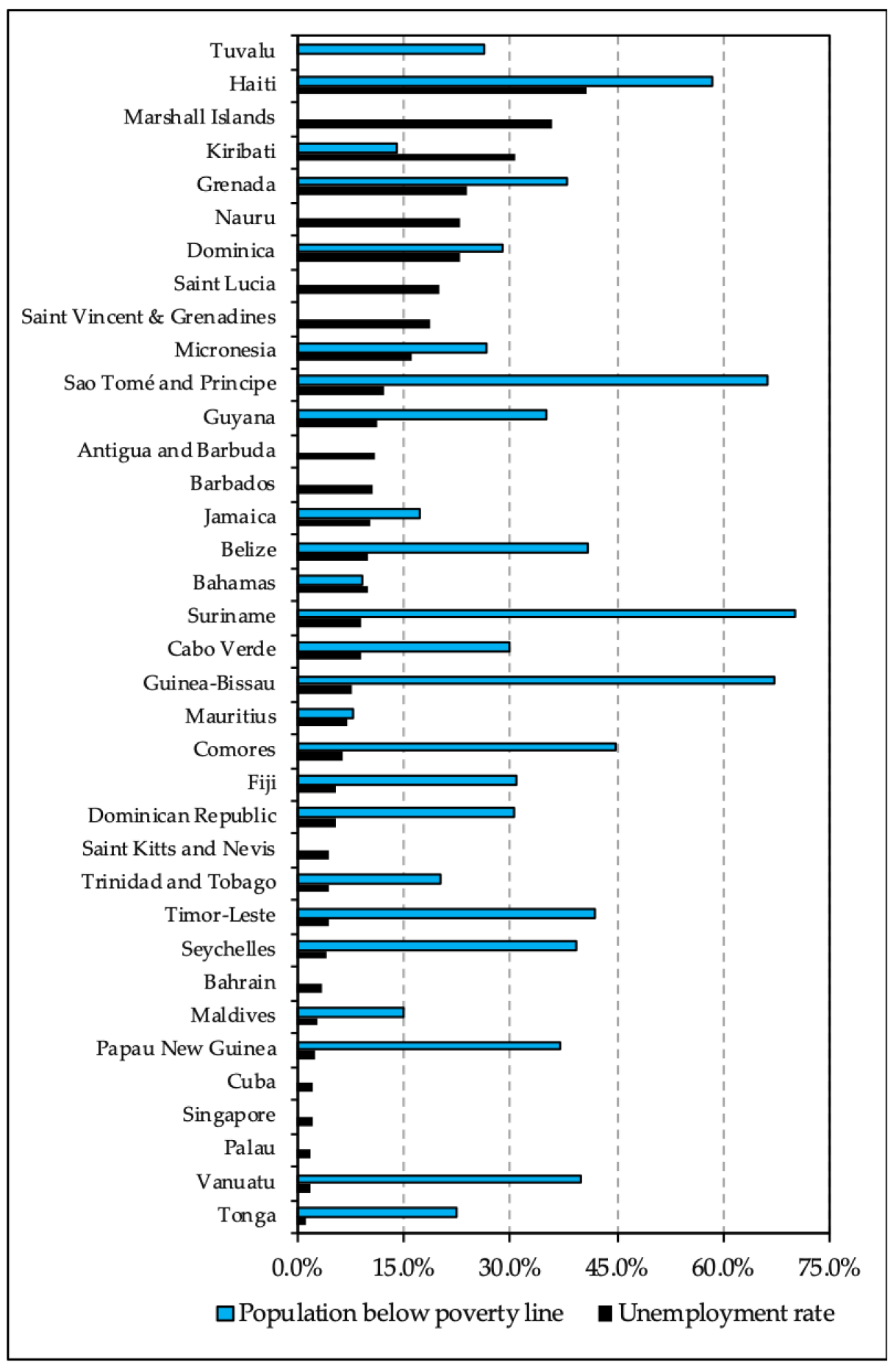

Figure 8. Correlation between unemployment rate and poverty (population living below poverty lines). Loss of livelihood and income opportunity from extreme climate events, disasters and politically often leads to unstable environment [33].

\section{Institutional and Policy Context of SIDS for DRR and Water Security Planning}

As the previous sections show, disasters, climate change, and low levels of water security can hinder SIDS on their way to sustainable development. Good governance, adaptation and mitigation measures are therefore needed [13]. The Sendai framework includes some targets on the spread of DRR strategies and the availability of early warning systems (see earlier); Integrative Water Resource Management (IWRM) is part of the targets and goals set in SDG 6 (see Appendix A) [72]. 
However, having these measures in place is by itself not enough of an indicator of good governance. In SIDS, DRR and climate change often require similar measures [55]. The integration of the two domains remains challenging for SIDS, and the risk of duplication and conflicts between policies is high. Similarly, having a water policy in place does not necessarily mean it is effective, for example, the water policy of Saint Kitts and Nevis dates to 1956. Many challenges arise because of the limited resources and capacity of SIDS; they often need external funding, technical and human capacity to formulate and implement policies [47]. In some countries, traditional or customary land usage can also hinder the implementation of water policies. It is noted that SIDS score low or medium-low on the degree of implementation of IWRM policy [73]. The UNEP-DHI initiative scores SDG 6.5 implementation based on the global baseline assessment on SDG indicator 6.5.1 and on country level surveys that assess and reflect on the progress and outcomes of the IWRM implementation. The surveys measure the enabling environment for IWRM, the institutions and participation, the management instruments, and financing. Exceptions such as Cuba that report a high score, exist but are rare.

Three case studies are selected for examining how water management and DRR strategies are formulated and implemented in SIDS. These case studies represent low and medium score in the IWRM portal and are upper-middle to high income countries as per the World Bank classification system. Also, each case study is from a different geographic cluster of SIDS.

\subsection{Trinidad and Tobago (Caribbean Cluster)}

Trinidad and Tobago, a mountainous state in the Caribbean, first formulated a water policy and IWRM plan in 2000 and revised it in 2017, with the vision to provide a reliable water supply for present and future demands [38]. When it comes to water availability, Trinidad and Tobago's groundwater volume of $144 \times 10^{9} \mathrm{~m}^{3}$ is the predominant source of freshwater, along with rainfall (average annual rainfall is $2200 \mathrm{~mm}$ /year), for which projections show a declining trend in the future [74]. As Figure 9 shows, rainfall can be as low as around $1200 \mathrm{~mm}$ /year to almost $2000 \mathrm{~mm} /$ year [75]. The groundwater resources are highly vulnerable to salinization, and the islands are subject to floods, droughts, and storms. The policy addresses the issues with the previous water policy including integrated watershed and coastal management, water pricing, and good data quality, relating to SDG 6.1, 6.2. 6.3 and 6.4 [76]. Other challenges related to water security are inadequate infrastructure, lack of integrated water resources management, and lack of provisions.

Trinidad and Tobago have recently formulated an IWRM that covers initiatives to upgrade the water infrastructure and involve community stakeholders while setting up an institutional framework [38]. Other targets include implementing water loss reduction and a wastewater management program and setting up a monitoring network. The policy also emphasizes the importance of mainstreaming water into other policies, as socio-economic and socio-political transitions could affect or can be affected by the IWRM. The government aims to formulate a framework to increase resilience of the islands. The different aspects of water security are also discussed with chapters on governance and legislation, ecosystems, water supply, and quality, economic activities and water-related disasters and climate change [38]. Regarding disasters, an integrated flood management program will be formulated. The document stresses the importance of good cooperation between different government entities and mechanisms for cooperation will be put into place. Trinidad and Tobago scores low on the degree of implementation of the IWRM, however, the revised IWRM policy of 2017 is not included in the survey yet [73].

The disaster management policy of the island, Disasters Measures Act Chapter 16:50, dates to 1978 and is not equipped to deal with present challenges [77]. In 1998 and 2008 efforts were made to develop a new legislation deriving from the assessment (2008) and review of best practices such as St Lucia's Disaster Management Act (2006) and several recommendations were formulated, including setting up a comprehensive approach that build resilience communities. Additionally, in 2011, the government of Trinidad and Tobago adopted a national climate change policy outlining the impact of 
climate change on various sectors and the actions to be taken [77]. Just like the IWRM-related policy, the document stresses the importance of the integration of climate change into other policies and the importance of aligning new policy with already existing ones such as the National Environmental Policy (2006). The policy objective to provide a sustainable water supply is explicitly mentioned with implementation assigned to the Multilateral Environmental Agreements Unit of the Ministry of Housing and the Environment. The emphasis on cooperation between agencies is set in the agenda, with clear strategy on free exchange of information and data among ministries and agencies.

\subsection{Maldives (AIMS Cluster)}

A low-lying SIDS, the Maldives consists of around 1200 atoll islands. The predominant source of freshwater is groundwater $\left(0.003 \times 10^{9} \mathrm{~m}^{3}\right)$ that consists of thin freshwater lenses on top of saline water close to the surface, and that is highly vulnerable to salination and other forms of pollution [39]. Almost $87 \%$ of the population is dependent on rainwater harvesting for their freshwater needs. As Figure 9 shows, annual rainfall does not vary too much although there are low years such as 1995 and 2011 with less than $2000 \mathrm{~mm}$ /year [78]. Part of the freshwater demand is also met through desalination of water; almost every resort has their desalination plant, and desalinated water is transported on ships to outer islands during the dry season [79]. The tsunami of 2004 stimulated the government to provide every household with a rainwater tank. Noting the increasing intensity and frequency of climatic turbulences and extreme events as shown in Figure 2, in 2017, the government of the Maldives formulated a national water and sewerage policy with the aim to provide equate water supply and the sustainable management of water resources; it is aligned with the constitution and SDG 6 [78]. It also stresses the importance of climate resilient policy measures and infrastructure. The policy document lists other related policies such as the Maldives Climate Change Policy Framework 2015. It is important to note that Maldives scores medium-low on the degree of implementation [73].

The island state has several climate and disaster risk policies in place, noting that it is classified highly vulnerable to disasters such as floods, storms and droughts, and to impacts of climate change [80]. The National Adaptation Plan for Action (NAPA) sets out the priority areas for action; these include water resources and tourism [80]. As many disasters will be exacerbated by climate change, a joint DRR and climate change adaptation approach for 2010-2020 is adopted to facilitate cooperation between policy makers, experts and other stakeholders working in the different sectors and to set up institutions and mechanisms for good governance at all levels [81]. The policy document stresses the importance of mainstreaming disaster risk and climate change in water-related programmes. The climate change policy framework also aims at enabling cooperation between different stakeholders and at incorporating existing and future climate change measures into related programmes in other sectors with focus on the priority areas formulated in the NAPA [81].

\subsection{Tuvalu (Pacific Cluster)}

A low-lying island state in the Pacific region, Tuvalu has very limited permanent freshwater resources and mostly brackish groundwater. Its groundwater volume is estimated to be $0.0004 \times 10^{9} \mathrm{~m}^{3}$ [39]. Tuvalu is highly vulnerable to climate change and mainly affected by storms and droughts. Freshwater resources and water supply on Tuvalu are significantly impacted by El Nino southern oscillation (ENSO) which creates high variability in average annual rainfall. Noting that rainwater harvesting is the primary source of drinking water, climate variability is likely to lead to water scarcity, creating water shortages [82]. Annual rainfall in Tuvalu is around $3000 \mathrm{~mm} /$ year (Figure 9) [83]. Desalination plants serve as back-up plans to provision water during dry periods. The government of Tuvalu formulated a Sustainable and Integrated Water and Sanitation Policy 2012-2021 to ensure access to sustainable water and sanitation provisions [82]. The policy is connected to amongst others Te Kaniva (National Climate Change Policy, 2012-2021), the National Action Plan to Combat Land Degradation and Drought (NAP, 2006), and the National Adaptation Program of Action (NAPA, 2007). More details in Table 2. 
Linking sustainable water management to the impacts of climate change is one of the leading principles of the Sustainable and Integrated Water and Sanitation Policy 2012-2021 [82]. The policy document installed by the government of Tuvalu ties with the vision outlined in SDG 6: managing the water supply, and SDG 11 addressing climate change and disasters impacts, more so in the context of its influence on water resources. The development of an early warning system to mitigate the effects of for example droughts, included in the policy, is a milestone to integrated solutions for DRR and water security. It is important to note is that all the measures to be taken include a component to build capacity and resilience in the different communities and to engage them is coming up with new mechanisms and institutions. It also stresses the importance of cooperation between various government agencies working on similar sectors. Tuvalu scores medium-low on the degree of implementation [73].

Tuvalu also has several disaster risk and climate change policies in place including Te Kaniva (2012-2021), NAP, NAPA, and the National Strategic Action Plan for Climate Change and Disaster Risk Management (NSAP, 2012-2016). Te Kaniva and NSAP are directly to each other; Te Kaniva investigates climate change impacts and climate-related disasters while NSAP looks into more anthropological disasters $[84,85]$. Both these documents stress the importance of mainstreaming its actions and principles into other sectors, such as in the Water Policy. Because of the linkages between climate change and disaster risk, Tuvalu has chosen to integrate policies and measures. Water management is explicitly stated as one of the critical issues related to climate change, and DRR. Increasing water security is an essential outcome of both policies. The collective account of related polices in these three regions is shown in Table 2.

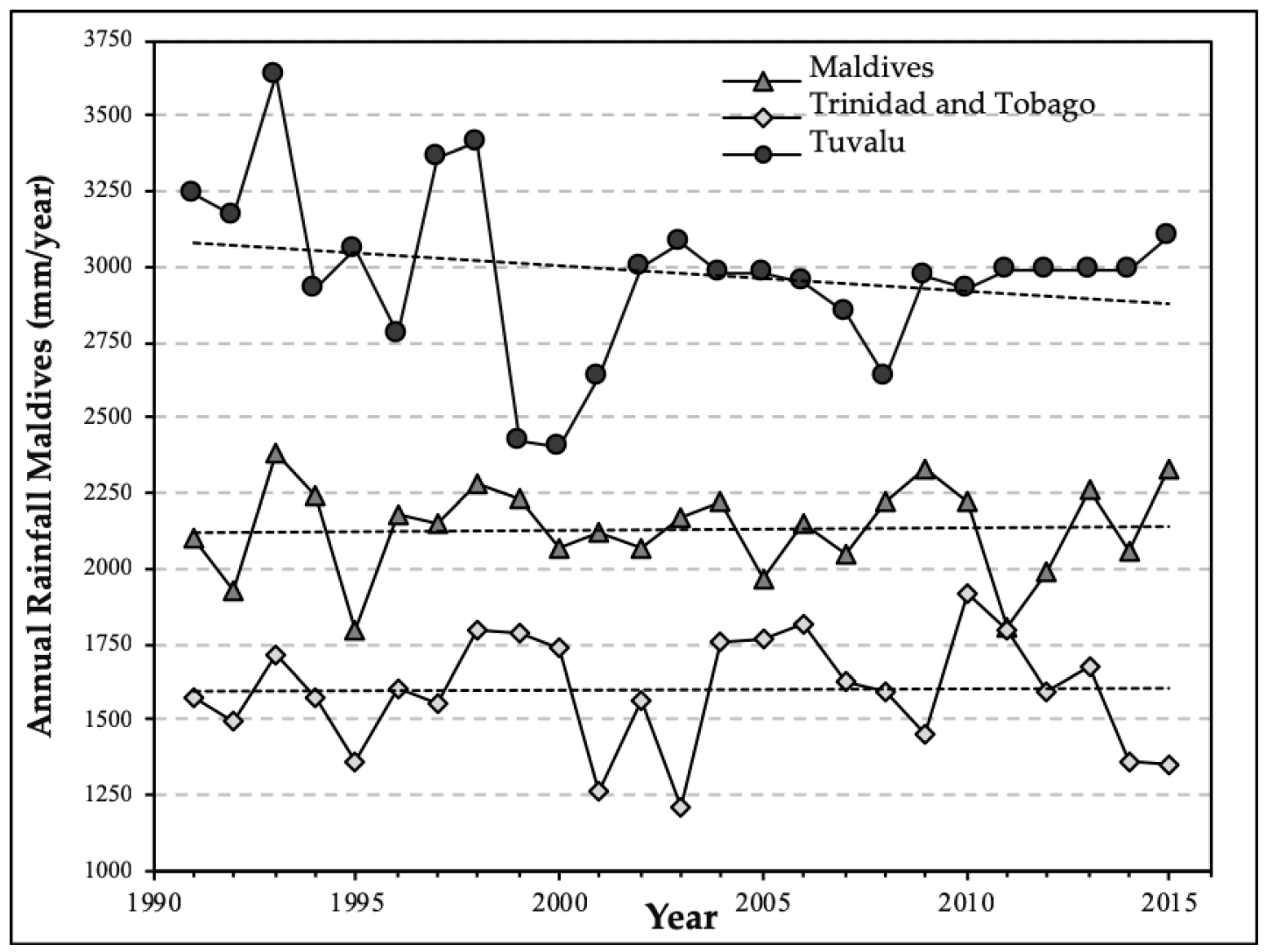

Figure 9. Average annual rainfall trend in Trinidad and Tobago, Maldives and Tuvalu, of which Tuvalu shows high temporal dynamics $[74,78,83]$. 
Table 2. Water policy and climate change and disaster risk reduction policy in selected case studies.

\begin{tabular}{|c|c|c|c|}
\hline & Trinidad and Tobago & Maldives & Tuvalu \\
\hline Water Policy & $\begin{array}{l}\text { National Integrated Water } \\
\text { Resources Management } \\
\text { Policy (2017) }\end{array}$ & $\begin{array}{l}\text { National Water and } \\
\text { Sewerage Policy (2017) }\end{array}$ & $\begin{array}{l}\text { Sustainable and Integrated } \\
\text { Water and Sanitation Policy } \\
\text { 2012-2021 }\end{array}$ \\
\hline \multirow{5}{*}{$\begin{array}{l}\text { Climate Change } \\
\text { and DRR Policy }\end{array}$} & $\begin{array}{l}\text { Disasters Measures Act } \\
\text { Chapter 16:50 (1978) }\end{array}$ & $\begin{array}{l}\text { National Adaptation Plan } \\
\text { for Action (NAPA, 2006) }\end{array}$ & $\begin{array}{l}\text { Te Kaniva (National Climate } \\
\text { Change Policy 2012-2021) }\end{array}$ \\
\hline & \multirow{4}{*}{$\begin{array}{l}\text { National Climate Change } \\
\text { Policy (2011) }\end{array}$} & $\begin{array}{l}\text { The Climate Change Policy } \\
\text { Framework (2015) }\end{array}$ & $\begin{array}{l}\text { National Action Plan to } \\
\text { Combat Land Degradation } \\
\text { and Drought (NAP, 2006) }\end{array}$ \\
\hline & & $\begin{array}{l}\text { Strategic National Action } \\
\text { Plan for DRR and Climate } \\
\text { Change Adaptation } \\
\text { 2010-2020 }\end{array}$ & $\begin{array}{l}\text { National Adaptation Program } \\
\text { of Action (NAPA) (2007) }\end{array}$ \\
\hline & & $\begin{array}{l}\text { The Disaster Management } \\
\text { Act (2015). }\end{array}$ & \multirow{2}{*}{$\begin{array}{l}\text { National Strategic Action Plan } \\
\text { for Climate Change and } \\
\text { Disaster Risk Management } \\
\text { (NSAP, 2012-2016) }\end{array}$} \\
\hline & & $\begin{array}{l}\text { Joint DRR and climate } \\
\text { change adaptation } \\
\text { approach for } 2010-2020\end{array}$ & \\
\hline
\end{tabular}

\section{Conclusions}

The assessment shows us that disaster risk, climate change, and water security are important challenges for SIDS that are linked together and that will become more pressing in the future unless better and more funding for governance is put into place. Disaster risks and climate change can significantly impact freshwater resources and levels of water security planning. Most SIDS are showing increasingly irregular rainfall patterns and more than three quarters of SIDS are expected to have a decline in rainfall [86]. Changes in rainfall will especially impact low-lying SIDS that are mostly reliant on rainwater harvesting for their freshwater provisioning needs. Furthermore, if no comprehensive and efficient governance policies on DRR and IWRM are formulated, disasters and low water security scenarios can adversely affect SIDS economically through aspects viz., loss of natural resources, societies can face forced migration, and in the environmental context, the degradation of ecosystems. Note that, $70 \%$ of SIDS already show negative migration rate with many highly educated people leaving the countries, contributing to increasing poverty and loss of human capital, thereby affecting SIDS's capacity to cope with natural, social, economic and financial stress [33]. As discussed, poverty and social instability can cause further environmental degradation. It is anticipated that good governance can help integrate different measures to increase water security and disaster risk resilience, and thus empower communities and vulnerable groups in society to adapt and transform into resilient societies. Through capacity building of communities, vulnerable groups can benefit from effective governance and policy measures, possibly leading to situation of less conflicts and more political stability, and the improving of the enabling environment in which water security, DRR, and climate change adaptation takes place.

A common feature of the above described case studies is their capacity to understand that cooperation between different government agencies, experts and other stakeholders is prerequisite for good governance. They also stress the importance of mainstreaming water issues, climate change, and DRR in all sectors and different policies. As noted in Maldives and Tuvalu, SIDS increasingly recognize the interlinkages between disasters and climate change and to an extent on how these emerging crises can influence their future water security. The notion of interrelated policies is gaining momentum to enhance and better implementation of the IWRM agenda, climate change planning, and DRR strategies. Looking at what contributes to the low or medium-low score in the case study analysis, it is observed that a significant fraction of SIDS face issues finding enough financing for the implementation of their existing policies (IWRM and sustainable water management-related agenda). The presence of 
an enabling environment and management instruments remain a challenge as well [73]. Robinson's (2018) commentary on climate change adaptation in the Caribbean, shows similar problems with climate change policies, highlighting that the main challenge to implementation is financing, followed by technological limitations and organizational capacity [87]. Furthermore, enhancing international cooperation to support SIDS, particularly on WASH, and on the DRR strategies, is present in the goals and targets of SDG 6 and the Sendai Framework; reflecting the international recognition for enhanced support. Additionally, the SDG target 13.a emphasizes that the developed countries that are part of the United Nations Framework Convention on Climate Change, commit themselves to mobilizing $\$ 100$ billion every year to assist developing countries with their measures against climate change, with focused efforts for SIDS [13].

If SIDS want to achieve the SDG 6 agenda and the DRR targets of the Sendai framework, capacity development on different levels and various stakeholders is pertinent. Because of increased hydro-climatic instability, the past trends can only serve as useful to a certain extent while simulating future scenarios. Preparation to manage environmental and climate changes requires up-to-date and comprehensive data analysis and information base, to fully understand the impacts of disasters risks and water security planning gaps and needs and to formulate efficient and sufficient adaptation policies. As the case study's analysis reflect, formulating policy is not enough, implementation of the existing policies remains a challenge. This need can be addressed to some extent by mainstreaming DRR, climate change adaptation, and water security into all policies and developing a comprehensive approach towards these challenges, such as in the Maldives. Cooperation between different agencies and on different levels can reduce the risk of duplication of and conflicts between policies. Overall, in-depth and context specific investigation on DRR, climate change adaptation and water security can help create a deeper understanding of the scenarios, gaps and need. This paper presents a detailed account of disaster risk and water security-related challenges in SIDS with the goal to contribute towards better understanding of critical challenges for development planning.

Author Contributions: Conceptualization and methodology, N.N. and E.D.P.P.; formal analysis, J.G.; writing_-original draft preparation, J.G.; writing_review and editing, N.N and E.D.P.P.; supervision, N.N. and E.D.P.P.

Funding: This research is supported by the funds received by UNU-INWEH through the long-term agreement with Global Affairs Canada.

Acknowledgments: Thanks are due to Vladimir Smakhtin (UNU-INWEH) for the constructive comments on the paper. The authors are very grateful to the anonymous reviewers for their valuable comments and suggestions to improve the manuscript to the present level.

Conflicts of Interest: The authors declare no conflict of interest. 


\section{Appendix A}

Table A1. Disaster risk reduction and water security aspects as reflected in selected sustainable development goals, targets and indicators [88].

\begin{tabular}{|c|c|c|}
\hline SDG & Targets by 2030 & Indicators \\
\hline \multirow{8}{*}{$\begin{array}{l}\text { Goal 6: Clean water } \\
\text { and sanitation }\end{array}$} & $\begin{array}{l}6.1 \text { Achieve universal and equitable access to safe and affordable drinking } \\
\text { water for all. }\end{array}$ & 6.1.1 Proportion of population using safely managed drinking water services. \\
\hline & $\begin{array}{l}\text { 6.2 Access to adequate and equitable sanitation and hygiene for all and end } \\
\text { open defecation. Special attention to the needs of women and girls and those } \\
\text { in vulnerable situations. }\end{array}$ & $\begin{array}{l}\text { 6.2.1 Proportion of population using safely managed sanitation services, } \\
\text { including a hand-washing facility with soap and water. }\end{array}$ \\
\hline & $\begin{array}{l}6.3 \text { Improve water quality by reducing pollution, eliminating dumping and } \\
\text { minimizing release of hazardous chemicals and materials. }\end{array}$ & $\begin{array}{l}\text { 6.3.1 Proportion of wastewater safely treated. } \\
\text { 6.3.2 Proportion of bodies of water with good environmental water quality. }\end{array}$ \\
\hline & $\begin{array}{l}\text { 6.4 Substantially increase water-use efficiency across all sectors and ensure } \\
\text { sustainable withdrawals and supply of freshwater to address water scarcity } \\
\text { and to substantially reduce the number of people suffering from } \\
\text { water scarcity. }\end{array}$ & $\begin{array}{l}\text { 6.4.1 Change in water-use efficiency over time. } \\
\text { 6.4.2 Level of water stress: how much freshwater is withdrawn from available } \\
\text { freshwater resources. }\end{array}$ \\
\hline & $\begin{array}{l}6.5 \text { Implement integrated water resources management at all levels, including } \\
\text { through transboundary cooperation as appropriate. }\end{array}$ & $\begin{array}{l}\text { 6.5.1 Degree of integrated water resources management implementation }(0-100) \text {. } \\
\text { 6.5.2 Proportion of transboundary basin area with an operational arrangement } \\
\text { for water cooperation. }\end{array}$ \\
\hline & $\begin{array}{l}\text { 6.6 Protect and restore water-related ecosystems, including mountains, forests, } \\
\text { wetlands, rivers, aquifers, and lakes }\end{array}$ & 6.6.1 Change in the extent of water-related ecosystems over time. \\
\hline & $\begin{array}{l}\text { 6.a Expand international cooperation and capacity-building support to } \\
\text { developing countries in water- and sanitation-related activities and } \\
\text { programmes, including water harvesting, desalination, water efficiency, } \\
\text { wastewater treatment, recycling and reuse technologies. }\end{array}$ & $\begin{array}{l}\text { 6.a.1 Amount of water- and sanitation-related official development assistance } \\
\text { that is part of a government-coordinated spending plan. }\end{array}$ \\
\hline & $\begin{array}{l}\text { 6.b Support and strengthen the participation of local communities in } \\
\text { improving water and sanitation management. }\end{array}$ & $\begin{array}{l}\text { 6.b.1 Proportion of local administrative units with established and operational } \\
\text { policies and procedures for participation of local communities in water and } \\
\text { sanitation management. }\end{array}$ \\
\hline
\end{tabular}


Table A1. Cont.

\begin{tabular}{ll}
\hline SDG & Targets by 2030 \\
\hline $\begin{array}{l}\text { 11.1 Ensure access for all to adequate, safe and affordable housing and basic } \\
\text { services and upgrade slums. }\end{array}$ & $\begin{array}{l}\text { 11.2 Provide access to safe, affordable, accessible and sustainable transport } \\
\text { systems for all. Improve road safety, notably by expanding public transport, } \\
\text { with special attention to the needs of those in vulnerable situations, women, } \\
\text { children, persons with disabilities and older persons. }\end{array}$ \\
$\begin{array}{l}\text { 11.3 Enhance inclusive and sustainable urbanization. Enhance capacity for } \\
\text { participatory, integrated and sustainable human settlement planning and } \\
\text { management in all countries. }\end{array}$ \\
\hline
\end{tabular}

Goal 11. Make cities and human settlements inclusive,

safe,

\section{resilient and}

sustainable

\section{Indicators}

11.1.1 Proportion of urban population living in slums, informal settlements or inadequate housing.

11.2.1 Proportion of population that has convenient access to public transport, by sex, age, and persons with disabilities.

11.3.1 Ratio of land consumption rate to population growth rate. 11.3.2 Proportion of cities with a direct participation structure of civil society in urban planning and management that operate regularly and democratically.

11.4.1 Total expenditure (public and private) per capita spent on the preservation, protection and conservation of all cultural and natural heritage, by type of heritage (cultural, natural, mixed and World Heritage Centre designation), level of government (national, regional and local/municipal), type of expenditure (operating expenditure/investment) and type of private funding (donations in kind, private non-profit sector and sponsorship).

11.5 Significantly reduce the number of deaths and the number of people affected by disasters. Substantially decrease the direct economic losses relative to global gross domestic product caused by disasters, including water-related disasters. Focus on protecting the poor and people in vulnerable situations.

11.6 Reduce the negative environmental impact of cities (per capita), including by paying special attention to air quality and municipal and other waste management.

11.5.1 Number of deaths, missing persons and persons affected by disaster per 100,000 people.

11.5.2 Direct disaster economic loss about global GDP, including disaster damage to critical infrastructure and disruption of basic services.

11.6.1 How much urban solid waste is regularly collected and adequately discharged of, of the total urban solid waste generated by cities 11.6.2 Annual mean levels of fine particulate matter (e.g., PM2.5 and PM10) in cities (population weighted)

11.7 Provide universal access to safe, inclusive and accessible, green and public spaces. particularly for women and children, older persons and persons with disabilities.

11.7.1 Average share of the built-up area of cities that is open space for public use for all, by sex, age, and persons with disabilities.

11.7.2 Proportion of victims of physical or sexual harassment, by sex, age, disability status and place of occurrence, in the previous 12 months.

11.a Support positive economic, social and environmental links between urban, peri-urban and rural areas by strengthening national and regional development planning. 11.a.1 Proportion of population living in cities that implement urban and regional development plans integrating population projections and resource needs, by size of city. 
Table A1. Cont.

\begin{tabular}{ll}
\hline SDG & Targets by $\mathbf{2 0 3 0}$ \\
\hline \multirow{2}{*}{$\begin{array}{l}\text { Goal 11. Make cities } \\
\text { and human } \\
\text { settlements inclusive, } \\
\text { safe, }\end{array}$} & $\begin{array}{l}\text { 11.b Substantially increase the number of cities and human settlements } \\
\text { adopting and implementing integrated policies and plans towards inclusion, } \\
\text { resource efficiency, mitigation and adaptation to climate change, resilience to } \\
\text { resilient and } \\
\text { sustainable }\end{array}$ \\
\cline { 2 - 2 } & $\begin{array}{l}\text { Reduction 2015-2030. } \\
\text { 11.c Support least developed countries, including through financial and } \\
\text { technical assistance, in building sustainable and resilient buildings utilizing } \\
\text { local materials. }\end{array}$ \\
\hline
\end{tabular}

13.1 Strengthen resilience and adaptive capacity to climate-related hazards and natural disasters in all countries.

Indicators

11.b.1 Proportion of local governments that adopt and implement local disaster

risk reduction strategies in line with the Sendai Framework for Disaster Risk

Reduction 2015-2030.

11.b.2 Number of countries with national and local disaster risk reduction strategies.

11.c.1 Proportion of financial support to the least developed countries that is

allocated to the construction and retrofitting of sustainable, resilient and resource-efficient buildings utilizing local materials.

13.1.1 Number of countries with national and local disaster risk

reduction strategies.

13.1.2 Number of deaths, missing persons and persons affected by disaster per 100,000 people.

13.2.1 Number of countries that have communicated the establishment or operationalization of an integrated policy/strategy/plan which increases their

13.2 Integrate climate change measures into national policies, strategies, and planning. ability to adapt to the adverse impacts of climate change, and foster climate resilience and low greenhouse gas emissions development in a manner that does not threaten food production (including a national adaptation plan, nationally determined contribution, national communication, biennial update report or other).

Goal 13. Take urgent action to combat climate change and its impacts (climate action)

13.3 Improve education, awareness-raising and human and institutional capacity on climate change mitigation, adaptation, impact reduction, and early warning.

13.a Implement the commitment undertaken by developed-country parties to the United Nations Framework Convention on Climate Change to-mobilizing jointly $\$ 100$ billion annually to address the needs of developing countries for mitigation actions and fully operationalize the Green Climate Fund.

13.b Promote mechanisms for raising capacity for effective climate change-related planning and management in least developed countries and small island developing States, including focusing on women, youth and local and marginalized communities.
13.3.1 Number of countries that have integrated mitigation, adaptation, impact reduction, and early warning into primary, secondary and tertiary curricula. 13.3.2 Number of countries that have communicated the strengthening of institutional, systemic and individual capacity-building to implement adaptation, mitigation, and technology transfer, and development actions.

13.a.1 Mobilized amount of United States dollars per year starting in 2020 accountable towards the $\$ 100$ billion commitment.

13.b.1 Number of least developed countries and small island developing States that are receiving specialized support, and amount of support, including finance, technology, and capacity-building, for mechanisms for raising capacities for effective climate change-related planning and management, including focusing on women, youth and local and marginalized communities. 


\section{References}

1. SIDS Partnership Framework. Available online: https://sustainabledevelopment.un.org/partnership/?p $=7891$ (accessed on 2 November 2018).

2. About AOSIS. Available online: http:/ / aosis.org/about/ (accessed on 3 December 2018).

3. Sjöstedt, M.; Povitkina, M. Vulnerability of Small Island Developing States to Natural Disasters. J. Environ. Dev. 2017, 26, 82-105. [CrossRef]

4. Intergovernmental Panel on Climate Change (IPCC). Global Warming of $1.5^{\circ}$ C; IPCC: Geneva, Switzerland, 2018.

5. Ranking the World's Most Water-Stressed Countries in 2040. Available online: https://www.wri.org/blog /2015/08/ranking-world-s-most-water-stressed-countries-2040 (accessed on 2 November 2018).

6. Water Stress to Affect $52 \%$ of World's Population by 2050. Available online: https://waterfootprint.org/en/ about-us/news/news/water-stress-affect-52-worlds-population-2050/ (accessed on 2 November 2018).

7. Australia Responds to Tuvalu Water Crisis. Available online: https://reliefweb.int/report/tuvalu/australi a-responds-tuvalu-water-crisis (accessed on 2 November 2018).

8. Pacific Nation Declares State of Emergency over Water Shortage. Available online: https://www.theguard ian.com/world/2011/oct/03/pacific-nation-state-emergency-water (accessed on 2 November 2018).

9. Boonreang, E. The Capacity Building in the Natural Disaster Management of Thailand. Int. J. Econ. Manag. Eng. 2015, 9, 1576-1581.

10. Oliver-Smith, A. The Concepts of Adaptation, Vulnerability, and Resilience in the Anthropology of Climate Change: Considering the Case of Displacement and Migration. In Anthropology and Climate Change: From Actions to Transformations, 2nd ed.; Crate, S., Nuttal, M., Eds.; Routledge: New York, NY, USA, 2016.

11. United Nations Educational, Scientific and Cultural Organization (UNESCO). Towards Climate Change Resilience-Minimising Loss and Damage in Pacific SIDS Communities; UNESCO: Apia, Samoa, 2017.

12. What Is Disaster Risk Reduction?-UNISDR. Available online: https://www.unisdr.org/who-we-are/wh at-is-drr (accessed on 6 November 2018).

13. United Nations Office for Disaster Risk Reduction (UNISDR). Sendai Framework for Disaster Risk Reduction 2015-2030; UNISDR: Geneva, Switzerland, 2015.

14. UN-Water. Water Security and the Global Water Agenda: An UN-Water Analytical Brief; United Nations University: Hamilton, ON, Canada, 2013.

15. Water Security Infographic. Available online: http://www.unwater.org/publications/water-security-info graphic/ (accessed on 2 October 2018).

16. Nurse, L.A.; McLean, R.F.; Agard, J.; Briguglio, L.P.; Duvat-Magnan, V.; Pelesikoti, N.; Tompkins, E.; Webb, A. Small islands. In Climate Change 2014: Impacts, Adaptation, and Vulnerability. Part B: Regional Aspects. Contribution of Working Group II to the Fifth Assessment Report of the Intergovernmental Panel on Climate Change, 1st ed.; Barros, V.R., Field, C.B., Dokken, D.J., Mastrandrea, M.D., Mach, K.J., Bilir, T.E., Chatterjee, M., Ebi, K.L., Estrada, Y.O., Genova, R.C., et al., Eds.; Cambridge University Press: Cambridge, UK; New York, NY, USA, 2004; pp. 1613-1654.

17. EM-DAT: The International Disasters Database. Available online: https://www.emdat.be/ (accessed on 14 November 2018).

18. Cost of Natural Disasters Increasing, Disaster-related Deaths Decreasing. Available online: http://ce ntralert.com/number-cost-natural-disasters-increasing-disaster-related-deaths-decreasing/ (accessed on 24 February 2019).

19. Average Precipitation in Depth (mm per year). Available online: https://data.worldbank.org/indicator/A G.LND.PRCP.MM?locations=AG-BS (accessed on 14 November 2018).

20. Disaster Risk and Vulnerability: The Role and Impact of Population and Society. Available online: https: / / www.prb.org/disaster-risk/ (accessed on 24 February 2019).

21. United Nations Human Settlements Programme (UN-Habitat). Urbanization and Climate Change in Small Island Developing States; UN-Habitat: Nairobi, Kenya, 2015.

22. Méheux, K.; Dominey-Howes, D.; Lloyd, K. Natural hazard impacts in small island developing states: A review of current knowledge and future research needs. Nat. Hazards 2006, 40, 429-446. [CrossRef]

23. United Nations Environment (UNEP). Global Environmental Outlook Small Island States; UNEP: Nairobi, Kenya, 2014. 
24. Granvorka, C.; Strobl, E. The Impact of Hurricane Strikes on Tourist Arrivals in the Caribbean. Tour. Econ. 2013, 19, 1401-1409. [CrossRef]

25. United Nations Office for Disaster Risk Reduction (UNISDR). Small Island Developing States, Disaster Risk Management, Disaster Risk Reduction, Climate Change Adaptation and Tourism; UNISDR: Geneva, Switzerland, 2013.

26. Shultz, J.; Cohen, M.; Hermosilla, S.; Espinel, Z.; McLean, A. Disaster risk reduction and sustainable development for small island developing states. Disaster Health 2016, 3, 32-44. [CrossRef] [PubMed]

27. Climate Change Is Wiping out the Secret to Fiji's International Rugby Success. Available online: https:/ / www.unenvironment.org/news-and-stories/story/climate-change-wiping-out-secret-fijis-inter national-rugby-success (accessed on 22 November 2018).

28. Mochizuki, J.; Mechler, R.; Hochrainer-Stigler, S.; Keating, A.; Williges, K. Revisiting the 'disaster and development' debate-Toward a broader understanding of macroeconomic risk and resilience. Clim. Risk Manag. 2014, 3, 39-54. [CrossRef] [PubMed]

29. International Union for Conservation of Nature (IUCN). Transforming Disaster Risk Reduction through Ecosystem Management in Oceania; IUCN ORO: Suva, Fiji, 2017.

30. Bello, O. Disasters, economic growth and fiscal response in the countries of Latin America and the Caribbean. CEPAL Rev. 2017, 121, 7-29.

31. United Nations Office for Disaster Risk Reduction (UNISDR). Disaster-related Data for Sustainable Development. In Sendai Framework Data Readiness Review 2017; UNIDR: Geneva, Switzerland, 2017.

32. Pacific Islands Launch Sendai Framework Monitor. Available online: https://www.unisdr.org/archive /57654 (accessed on 7 November 2018).

33. CIA The World Factbook. Available online: https://www.cia.gov/library/publications/the-world-factboo k/fields/2216.html\#52 (accessed on 8 November 2018).

34. World Health Organization (WHO); The United Nations Children's Fund (UNICEF). Progress on Drinking Water, Sanitation and Hygiene: 2017 Update and SDG Baselines; WHO; The UNICEF: Geneva, Switzerland, 2017.

35. United Nations International Children's Emergency Fund (UNICEF). Final Evaluation Improving WASH in Solomon Islands (IWASH-SI) Project; UNICEF: Suva, Fiji, 2017.

36. Belmar, Y.; McNamara, K.; Morrison, T. Water security in small island developing states: The limited utility of evolving governance paradigms. Wiley Interdiscip. Rev. Water 2015, 3, 181-193. [CrossRef]

37. Amnesty International. Where Is the Dignity in That? Women in Solomon Islands Slums Denied Sanitation and Safety; Amnesty International: London, UK, 2011.

38. Government of the Republic of Trinidad and Tobago. National Integrated Water Resource Management Policy; Ministry of Public Utilities: St Clair, Trinidad and Tobago, 2017.

39. IGRAC GGIS Viewer. Available online: https://apps.geodan.nl/igrac/ggis-viewer/viewer/twap/public/ default (accessed on 27 November 2018).

40. Funafuti Island Tuvalu. Available online: https://services.geodan.nl/public/document/AGRC0001XXXX/ api/data/AGRC0001XXXX/mim/Tuvalu_final.pdf_ol7jokkii (accessed on 16 September 2018).

41. Sandford, R. Storm Warning: Water and Climate Security in a Changing World, 1st ed.; Rocky Mountain Books: Victoria, BC, Canada, 2015.

42. World Meteorological Organization (WMO). Saving Paradise. Ensuring Sustainable Development; WMO: Geneva, Switzerland, 2005.

43. United Nations Educational, Scientific and Cultural Organization (UNESCO). Droughts in Small Coral Islands: Case Study, South Tarawa, Kiribati; International Hydrological Programme: Paris, France, 1999.

44. White, I.; Falkland, T. Management of freshwater lenses on small Pacific islands. Hydrogeol. J. 2009, 18, 227-246. [CrossRef]

45. Chilunga, F.; Rodriguez-Llanes, J.; Guha-Sapir, D. Rapid Urbanization is Linked to Flood Lethality in the Small Island Developing States (SIDS): A Modeling Study. Prehosp. Disaster Med. 2017, 32, s190. [CrossRef]

46. Mata-Lima, H.; Alvino-Borba, A.; Aguiar, R.; Drumond, J. Factors Affecting Flood Disasters in Small Island Developing States and Potential Adaptation Measures: The Case of Funchal City, Portugal. Environ. Qual. Manag. 2016, 25, 37-51. [CrossRef]

47. United Nations Environment (UNEP). Integrated Water Resources Management Planning Approach for Small Island Developing States; UNEP: Nairobi, Kenya, 2012. 
48. Kaly, U.; Pratt, C.; Howorth, R. A framework for managing environmental vulnerability in small island developing states. Dev. Bull. 2002, 58, 1-10.

49. United Nations Educational, Scientific, and Cultural Organization-International Hydrological Programme and UN Environment (UNEP). Transboundary Aquifers and Groundwater Systems of Small Island Developing States: Status and Trends, Summary for Policy Makers; UNEP: Nairobi, Kenya, 2016.

50. Office of the High Representative of Least Developed Countries, Landlocked Developing Countries, and Small Island Developing States (UN-OHRLLS). Small Island Developing States in Numbers: Biodiversity and Oceans; UN-OHRLLS: New York, NY, USA, 2017.

51. Partnerships for Small Island Developing States 2016; Steering Committee for Partnerships on SIDS: New York, NY, USA, 2016.

52. GDP Growth (Annual \%). Available online: https://data.worldbank.org/indicator/NY.GDP.MKTP.KD. ZG?end=2017\&locations=AG-BS-BB-CU-DM-DO-GD-GY-HT-KN-LC-VC-TT\&start=2000\&view=chart (accessed on 8 November 2018).

53. Caribbean Overview. Available online: https://www.worldbank.org/en/country/caribbean/overview (accessed on 17 October 2018).

54. Partnership Briefs for Small Island Developing States: Climate Change and Disaster Risk Management; Division for Sustainable Development United Nations Department of Economic and Social Affairs (UNDESA): New York, NY, USA, 2014.

55. Financing for Development and Small Island Developing States: A Snapshot and Ways Forward; United Nations Development Program (UNDP); United Nations Office of the High Representative for the Least Developed Countries, Landlocked Developing Countries and Small Island Developing States (UN-OHRLLS): New York, NY, USA, 2015.

56. Climate and Disaster Resilience Financing in Small Island Developing States; Organisation for Economic Co-operation and Development (OECD); The World Bank: Washington, DC, USA, 2016.

57. Making Development Co-Operation Work for Small Island Developing States; Organisation for Economic Co-operation and Development (OECD): Paris, France, 2018.

58. The Adaptation Fund and Small Island Developing States. Available online: https://www.adaptation-fund. org/adaptation-fund-small-island-developing-states / (accessed on 2 October 2018).

59. Pratt, S. The economic impact of tourism in SIDS. Ann. Tour. Res. 2015, 52, 148-160. [CrossRef]

60. Boto, I.; Biasca, R. Small Island Economies: From Vulnerabilities to Opportunities. In Brussels Rural Development Briefings; A Series of Meetings on ACP-EU Development Issues; 2012; Volume 27, pp. 1-4. Available online: https://brusselsbriefings.files.wordpress.com/2012/06/reader-br-27-small-island-eco nomies-vulnerabilities-and-opportunities.pdf (accessed on 27 November 2018).

61. Challenges and Opportunities for Tourism Development in Small Island Developing States; World Tourism Organization (UNWTMO): Madrid, Spain, 2012.

62. Maldives Facing 'Disaster' over Drinking Water Shortage. Available online: https://www.telegraph.co.uk/ news/worldnews/africaandindianocean/maldives/11276954/Maldives-facing-disaster-over-drinking-W ater-shortage.html (accessed on 3 October 2018).

63. Office of the High Representative of the Least Developed Countries, Landlocked Developing Countries and Small Island Developing States (UN-OHRLLS). Small Island Developing States in Numbers; UN-OHRLLS: New York, NY, USA, 2015.

64. Worlddata: The World in Numbers. Available online: https://www.worlddata.info/ (accessed on 27 November 2018).

65. Grey, D.; Sadoff, C.W. Sink or Swim? Water security for growth and development. Water Policy 2007, 9,545-571. [CrossRef]

66. Youth Are The Future: The Imperative of Youth Employment for Sustainable Development in the Caribbean; Caribbean Development Bank: Bridgetown, Barbados, 2015.

67. de la Croix, D.; Docquier, F.; Schiff, M. Brain Drain and Economic Performance in Small Island Developing States. In The Socio-Economic Impact of Migration Flows Effects on Trade, Remittances, Output, and the Labour Market, 1st ed.; Artal-Tur, A., Peri, G., Requena-Silvente, F., Eds.; Springer International Publishing: Cham, Switzerland, 2014; pp. 123-144.

68. Beating Unemployment in the Solomon Islands. Available online: http://blogs.worldbank.org/eastasiapa cific/beating-unemployment-in-the-solomon-islands (accessed on 15 October 2018). 
69. Gender Equality in Small Island Developing States; United Nations Educational, Scientific and Cultural Organization (UNESCO): Paris, France, 2014.

70. Romer, K.; Renzaho, A. Re-emerging conflict in the Solomon Islands? The underlying causes and triggers of the riots of April 2006. J. Peace Confl. Dev. 2007, 10, 1-23.

71. Solomon Islands Capital Honiara Calm after Riots by Flood Victims. Available online: http://www.abc.net. au/news /2014-05-19/solomons-riot-calm-flood-update/5461542 (accessed on 15 October 2018).

72. United Nations. Sustainable Development Goal 6: Synthesis Report on Water and Sanitation; United Nations: New York, NY, USA, 2018.

73. IWRM Data Portal. Available online: http://iwrmdataportal.unepdhi.org/index.html (accessed on 23 October 2018).

74. Average Monthly Temperature and Rainfall for Trinidad and Tobago from 1901-2015. Available online: http:/ / sdwebx.worldbank.org/climateportal/index.cfm?page=country_historical_climate\&ThisCCode =TTO (accessed on 3 December 2018).

75. Mycoo, M. Achieving SDG 6: Water resources sustainability in Caribbean Small Island Developing States through improved water governance. Nat. Resour. Forum 2017, 42, 54-68. [CrossRef]

76. Policies, Plans and Legislation. Available online: http://www.odpm.gov.tt/node/159\# (accessed on 19 October 2018).

77. National Climate Change Policy. Government of the Republic of Trinidad and Tobago: Port of Spain, Trinidad and Tobago, 2011.

78. Average Monthly Temperature and Rainfall for Maldives from 1901-2015. Available online: http://sdwebx.worldbank.org/climateportal/index.cfm?page=country_historical_climate\&ThisRegion= Asia\&ThisCCode=MDV (accessed on 3 December 2018).

79. Maldives Climate Change Policy Framework; Ministry of Environment and Energy Maldives: Male, Republic of Maldives, 2015.

80. Ministry of Environment and Energy; National Water and Sewerage Policy; Ministry of Environment and Energy: Male, Republic of Maldives, 2017.

81. Strategic National Action Plan for Disaster Risk Reduction and Climate Change Adaptation 2010-2020. The Republic of the Maldives: Male, Republic of Maldives, 2010.

82. Government of Tuvalu. Sustainable and Integrated Water and Sanitation Policy 2012-2021; SPC-Applied Geoscience and Technology Division (SOPAC): Suva, Fiji, 2013.

83. Average Monthly Temperature and Rainfall for Tuvalu from 1901-2015. Available online: http://sdwebx.w orldbank.org/climateportal/index.cfm?page=country_historical_climate\&ThisCCode=TUV (accessed on 3 December 2018).

84. National Strategic Action Plan for Climate Change and Disaster Risk Management 2012-2016; Government of Tuvalu: Funafuti, Tuvalu, 2012.

85. Te Kaniva: Tuvalu Climate Change Policy; Government of Tuvalu: Funafuti, Tuvalu, 2012.

86. AQUASTAT. Available online: http://www.fao.org/nr/water/aquastat/main/index.stm (accessed on 15 August 2018).

87. Robinson, S. Adapting to climate change at the national level in Caribbean small island developing state. Isl. Stud. J. 2018, 13, 79-100. [CrossRef]

88. Sustainable Development Goals. Available online: https://sustainabledevelopment.un.org/sdgs (accessed on 15 August 2018).

(C) 2019 by the authors. Licensee MDPI, Basel, Switzerland. This article is an open access article distributed under the terms and conditions of the Creative Commons Attribution (CC BY) license (http:/ / creativecommons.org/licenses/by/4.0/). 